\title{
Differential Expression of MicroRNAs between Eutopic and Ectopic Endometrium in Ovarian Endometriosis
}

\author{
Nicoletta Filigheddu, ${ }^{1}$ Ilaria Gregnanin, ${ }^{1}$ Paolo E. Porporato, ${ }^{2}$ Daniela Surico, ${ }^{1}$ \\ Beatrice Perego, ${ }^{1}$ Licia Galli, ${ }^{1}$ Claudia Patrignani, ${ }^{2}$ Andrea Graziani, ${ }^{2}$ and Nicola Surico ${ }^{1}$
}

\author{
${ }^{1}$ Laboratory of Oncological Gynecology, Department of Clinical and Experimental Medicine, and Biotechnology Center for \\ Applied Medical Research, University of Piemonte Orientale "Amedeo Avogadro", 28100 Novara, Italy \\ ${ }^{2}$ Laboratory of Biochemistry, Department of Clinical and Experimental Medicine, and Biotechnology Center for \\ Applied Medical Research, University of Piemonte Orientale "Amedeo Avogadro", 28100 Novara, Italy
}

Correspondence should be addressed to Nicoletta Filigheddu, nicoletta.filigheddu@med.unipmn.it

Received 12 March 2009; Revised 10 August 2009; Accepted 19 December 2009

Academic Editor: Sorin Draghici

Copyright ( $) 2010$ Nicoletta Filigheddu et al. This is an open access article distributed under the Creative Commons Attribution License, which permits unrestricted use, distribution, and reproduction in any medium, provided the original work is properly cited.

\begin{abstract}
Endometriosis, defined as the presence of endometrial tissue outside the uterus, is a common gynecological disease with poorly understood pathogenesis. MicroRNAs are members of a class of small noncoding RNA molecules that have a critical role in posttranscriptional regulation of gene expression by repression of target mRNAs translation. We assessed differentially expressed microRNAs in ectopic endometrium compared with eutopic endometrium in 3 patients through microarray analysis. We identified 50 microRNAs differentially expressed and the differential expression of five microRNAs was validated by real-time RT-PCR in other 13 patients. We identified in silico their predicted targets, several of which match the genes that have been identified to be differentially expressed in ectopic versus eutopic endometrium in studies of gene expression. A functional analysis of the predicted targets indicates that several of these are involved in molecular pathways implicated in endometriosis, thus strengthening the hypothesis of the role of microRNAs in this pathology.
\end{abstract}

\section{Introduction}

Endometriosis, defined as the growth of endometrial tissue outside the uterine cavity, is a common gynecological disease often resulting in chronic pelvic pain and infertility. The pathogenesis of endometriosis is likely multifactorial and several hypotheses have been suggested to explain the presence of ectopic endometrial tissue and stroma, such as retrograde menstrual reflux [1], immune system defects [2-10], and ectopic presence of endometrial stem cells originating the disease [11]. In addition, there is a growing body of evidence indicating the involvement of genetic factors in the etiology of endometriosis, as it has been calculated that there is a 6-9-fold increased prevalence of this pathology among the 1st-degree relatives of women with endometriosis, compared to the general population [12-18]. Extensive investigations have been performed to characterize the differences between the eutopic and ectopic endometrium in order to better understand and define the molecular basis of the disease and, indeed, several studies have revealed a distinct pattern of gene expression in eutopic and ectopic endometrium [19-24]. The differences in gene expression reported in these works include genes encoding proteins involved in cell adhesion, extracellular matrix remodeling, migration, proliferation, immune system regulation, and inflammatory pathways, thus accounting for the multiple mechanisms hypothesized to be responsible for the establishment of ectopic endometrial implants, including the adhesion of endometrial cells to the pelvic peritoneum, invasion into the mesothelium, and survival and proliferation of the ectopic endometrial cells.

MicroRNAs (miRNAs), members of a class of small noncoding RNA molecules, have a critical role in posttranscriptional regulation of gene expression by repression of target mRNAs translation. Originally identified in Caenorhabditis elegans [25], miRNAs have been shown to operate in a wide 


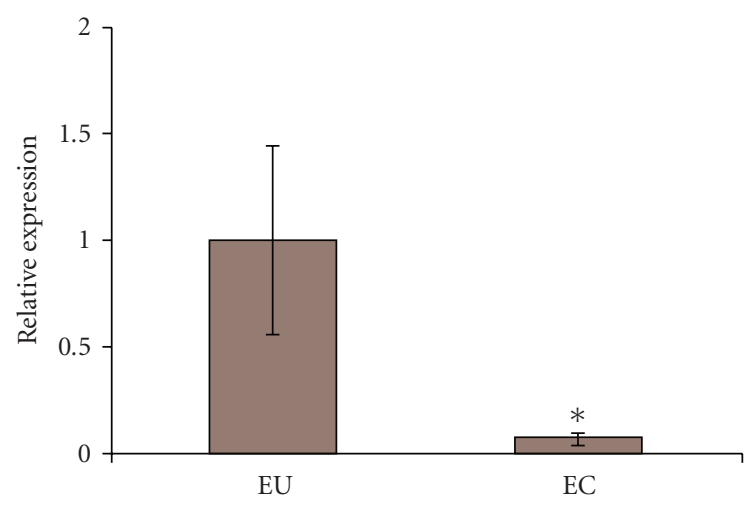

(a)

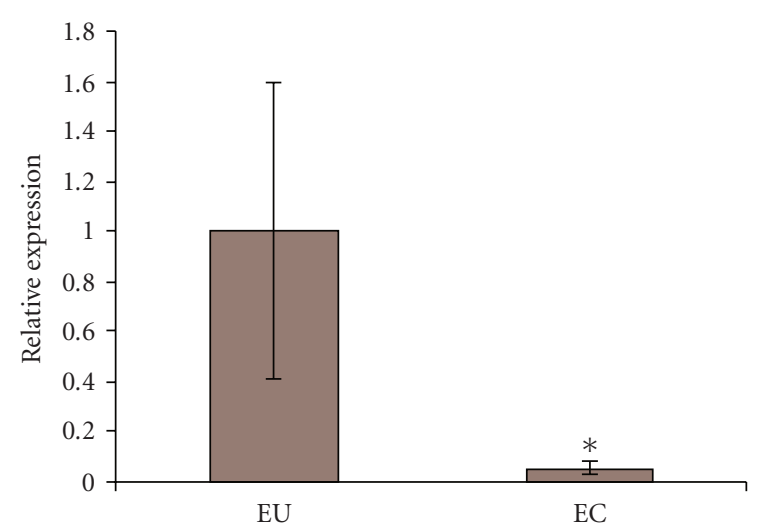

(c)

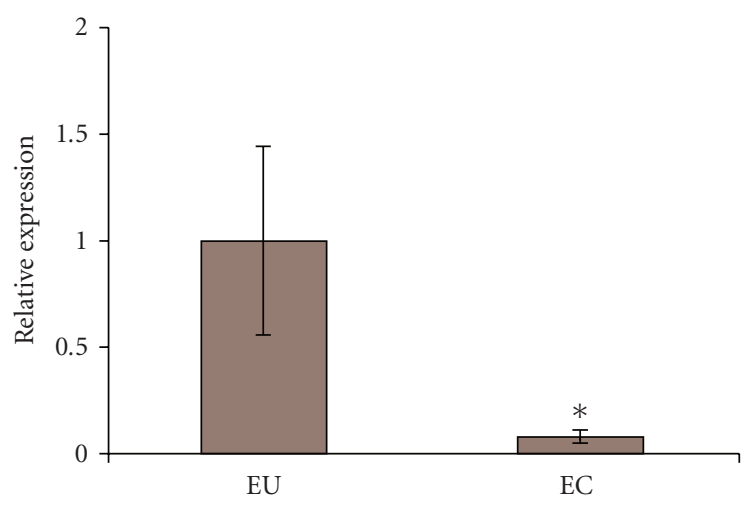

(b)

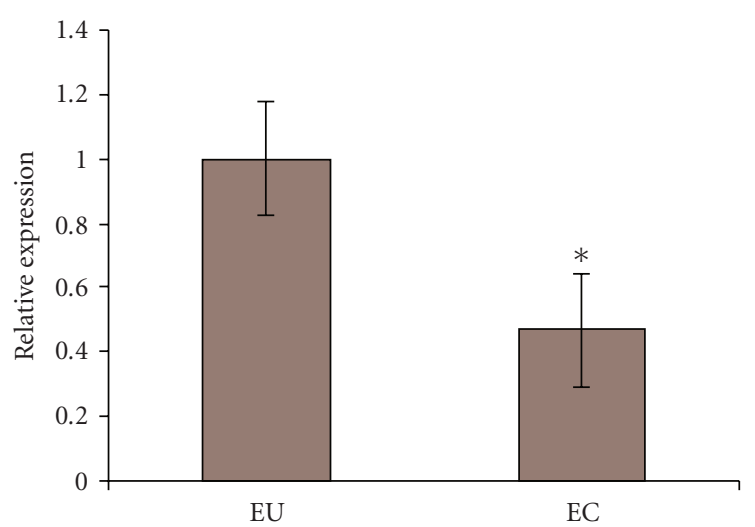

(d)

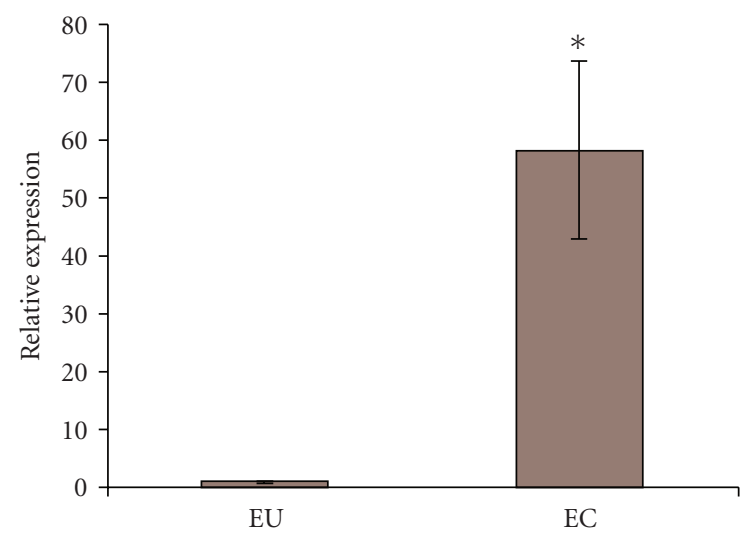

(e)

FIGURE 1: Differential expression of miRNAs in ectopic versus eutopic endometrium. The miRNAs selected for independent validation were among those with wider difference in expression between eutopic and ectopic endometrium. The differential expression of the selected miRNAs in the ectopic versus eutopic tissues was evaluated by real-time RT-PCR. The expression of each miRNA in eutopic tissue was set to 1. (a) hsa-miR-200a, (b) hsa-200b, (c) hsa-miR-200c, (d) hsa-miR-182, and (e) hsa-miR-202. ${ }^{*} P<.05$.

range of species, including humans. Computational predictions indicate that up to $30 \%$ of human genes are potential targets of miRNAs and that miRNAs compose $1 \%-5 \%$ of animal genomes [26-29]. MiRNA expression is tissue- and cell-specific [30-33]. It has been demonstrated that miRNAs are important in developmental processes as well as for other cellular activities involving cell growth, differentiation, and apoptosis. Moreover, several genes encoding miRNAs have been located at chromosomal fragile sites or regions of cytogenetic abnormalities associated with cancer and other disorders. Interestingly, miRNAs altered expression has been associated with tumorigenesis, and several studies have described differential expression of miRNAs in neoplastic versus normal tissue [34-38]. 

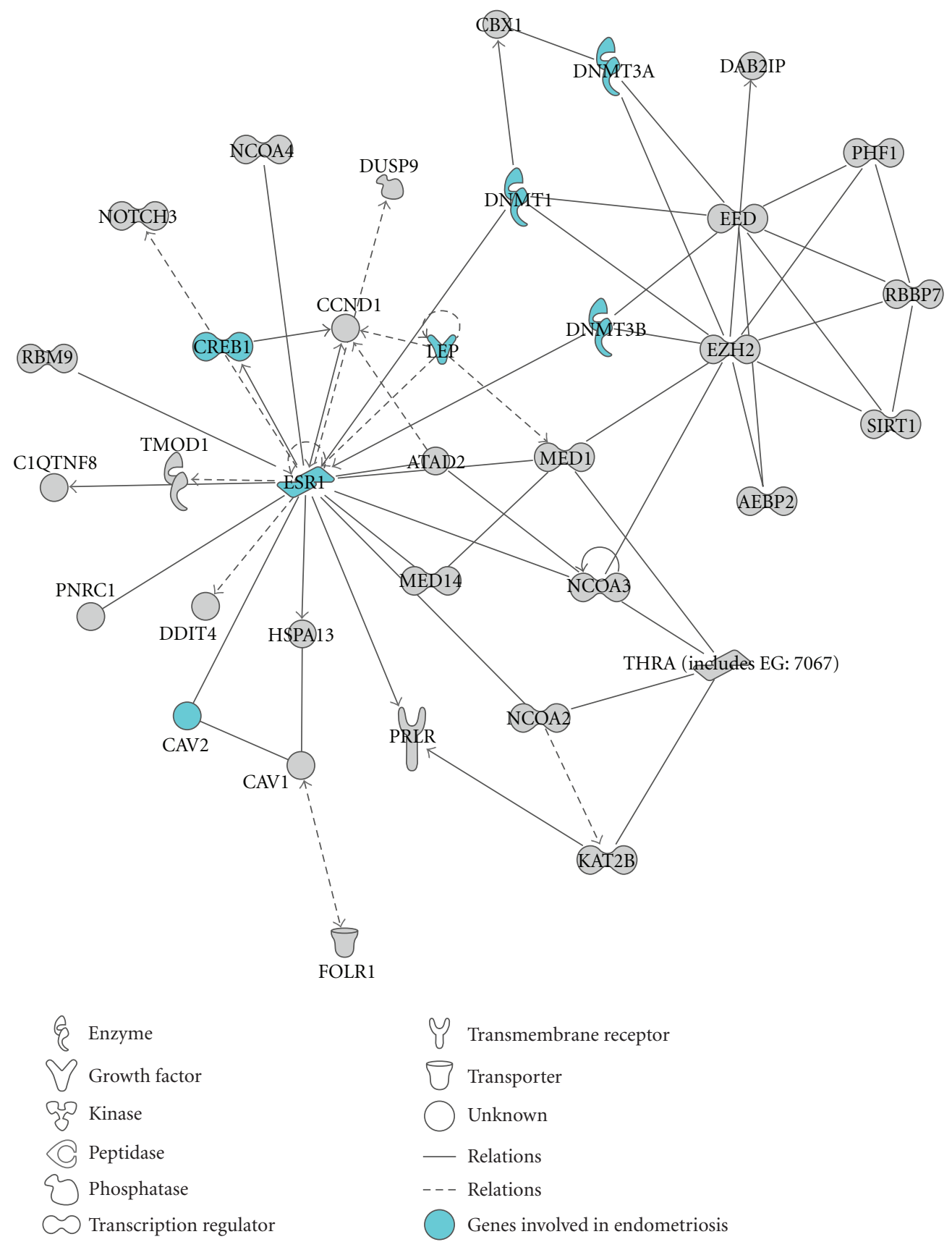

FigURE 2: Functional analysis of all the predicted targets of the differentially expressed miRNAs. Graphical representation of network \#2 obtained by IPA analysis. Genes are represented as nodes, and the biological relationship between two nodes is represented as a line. Every line is supported by at least one reference in literature. Highlighted, the genes involved in endometriosis according to IPA knowledge base.

Our study is aimed to investigate the differential expression of miRNAs in endometriosis by direct comparison between paired ectopic and eutopic endometrium samples. Once we identified the differentially expressed miRNAs, we validated 5 of them by an independent technique. Then, we identified in silico the predicted molecular targets of the differentially expressed miRNAs and we used a bioinformatics tool to investigate the molecular pathways in which these targets could be involved.

\section{Materials and Methods}

2.1. Tissue Collection. Subjects $(n=16)$ scheduled for surgery for chronic pelvic pain or infertility at the University of Piemonte Orientale-affiliated "Maggiore della Carità" Hospital were recruited to participate in this study. The study was approved by the "Maggiore della Carità" Hospital's Institutional Review Board and informed consent was obtained from all participants. None of the authors have any conflict 
TABLE 1: Differentially expressed miRNAs in ectopic versus eutopic endometrium. List of differentially expressed miRNAs whose expression value in ectopic endometrium was at least twofold higher or lower than in eutopic endometrium $P<.01$.

\begin{tabular}{|c|c|c|c|}
\hline Name & EU & EC & $P$-value \\
\hline hsa-miR-1 & 36.29 & $2,090.27$ & $.00 \mathrm{E}+00$ \\
\hline hsa-miR-100 & $7,517.73$ & $18,712.43$ & $.00 \mathrm{E}+00$ \\
\hline hsa-miR-101 & 341.51 & $2,348.69$ & $.00 \mathrm{E}+00$ \\
\hline hsa-miR-106a & $3,264.74$ & $1,510.10$ & $1.11 \mathrm{E}-16$ \\
\hline hsa-miR-106b & $2,996.55$ & $1,414.14$ & $.00 \mathrm{E}+00$ \\
\hline hsa-miR-126 & $10,373.88$ & $22,435.79$ & $.00 \mathrm{E}+00$ \\
\hline hsa-miR-130a & $1,634.84$ & $5,145.94$ & $.00 \mathrm{E}+00$ \\
\hline hsa-miR-130b & 673.04 & 249.86 & $.00 \mathrm{E}+00$ \\
\hline hsa-miR-132 & $3,699.14$ & $1,261.33$ & $.00 \mathrm{E}+00$ \\
\hline hsa-miR-143 & $8,104.26$ & $21,764.97$ & $.00 \mathrm{E}+00$ \\
\hline hsa-miR-145 & $10,992.36$ & $27,550.33$ & $.00 \mathrm{E}+00$ \\
\hline hsa-miR-148a & $2,623.73$ & $6,507.58$ & $.00 \mathrm{E}+00$ \\
\hline hsa-miR-150 & $1,621.96$ & $4,503.15$ & $.00 \mathrm{E}+00$ \\
\hline hsa-miR-17-5p & $4,517.66$ & $2,059.32$ & $.00 \mathrm{E}+00$ \\
\hline hsa-miR-182 & $1,998.92$ & 230.69 & $.00 \mathrm{E}+00$ \\
\hline hsa-miR-183 & 410.83 & 41.02 & $.00 \mathrm{E}+00$ \\
\hline hsa-miR-186 & 56.69 & 246.79 & $1.21 \mathrm{E}-14$ \\
\hline hsa-miR-196b & 380.45 & 14.13 & $.00 \mathrm{E}+00$ \\
\hline hsa-miR-199a & $4,481.27$ & $12,618.11$ & $.00 \mathrm{E}+00$ \\
\hline hsa-miR-200a & 582.95 & 33.22 & $.00 \mathrm{E}+00$ \\
\hline hsa-miR-200b & $17,643.11$ & 675.98 & $.00 \mathrm{E}+00$ \\
\hline hsa-miR-200c & $25,249.55$ & $1,391.63$ & $.00 \mathrm{E}+00$ \\
\hline hsa-miR-202 & 49.64 & 471.06 & $2.27 \mathrm{E}-13$ \\
\hline hsa-miR-20a & $5,278.72$ & $2,534.21$ & $9.05 \mathrm{E}-14$ \\
\hline hsa-miR-221 & $5,368.05$ & $10,915.55$ & $.00 \mathrm{E}+00$ \\
\hline hsa-miR-25 & $12,878.14$ & $6,328.31$ & $1.06 \mathrm{E}-14$ \\
\hline hsa-miR-28 & $1,465.55$ & $4,589.04$ & $.00 \mathrm{E}+00$ \\
\hline hsa-miR-299-5p & 202.34 & 452.17 & $5.18 \mathrm{E}-13$ \\
\hline hsa-miR-29b & 248.51 & $4,963.66$ & $.00 \mathrm{E}+00$ \\
\hline hsa-miR-29c & 295.40 & $10,562.63$ & $.00 \mathrm{E}+00$ \\
\hline hsa-miR-30e-3p & 299.19 & $1,003.48$ & $1.50 \mathrm{E}-14$ \\
\hline hsa-miR-30e-5p & 58.94 & 428.59 & $.00 \mathrm{E}+00$ \\
\hline hsa-miR-34a & 337.65 & 861.73 & $.00 \mathrm{E}+00$ \\
\hline hsa-miR-365 & 264.57 & $2,071.70$ & $.00 \mathrm{E}+00$ \\
\hline hsa-miR-368 & 297.52 & $1,882.43$ & $.00 \mathrm{E}+00$ \\
\hline hsa-miR-375 & $1,329.85$ & 13.62 & $.00 \mathrm{E}+00$ \\
\hline hsa-miR-376a & 64.20 & 522.49 & $.00 \mathrm{E}+00$ \\
\hline hsa-miR-379 & 175.21 & 601.12 & $7.19 \mathrm{E}-13$ \\
\hline hsa-miR-411 & 62.72 & 215.67 & $5.92 \mathrm{E}-16$ \\
\hline hsa-miR-425-5p & 961.30 & 329.99 & $.00 \mathrm{E}+00$ \\
\hline hsa-miR-486 & $2,824.50$ & 956.89 & $.00 \mathrm{E}+00$ \\
\hline hsa-miR-493-5p & 64.60 & 355.15 & $7.22 \mathrm{E}-12$ \\
\hline hsa-miR-503 & $2,084.95$ & 465.94 & $.00 \mathrm{E}+00$ \\
\hline hsa-miR-638 & $29,531.60$ & $11,202.65$ & $.00 \mathrm{E}+00$ \\
\hline hsa-miR-663 & $4,654.42$ & $1,943.14$ & $4.44 \mathrm{E}-15$ \\
\hline hsa-miR-671 & $2,052.70$ & 955.73 & $.00 \mathrm{E}+00$ \\
\hline hsa-miR-768-3p & $5,841.89$ & $2,901.78$ & $2.81 \mathrm{E}-06$ \\
\hline hsa-miR-768-5p & $5,321.54$ & $2,456,43$ & $.00 \mathrm{E}+00$ \\
\hline hsa-miR-93 & $2,614.63$ & 629.20 & $.00 \mathrm{E}+00$ \\
\hline hsa-miR-99a & $6,766.02$ & $18,369.57$ & $.00 \mathrm{E}+00$ \\
\hline
\end{tabular}




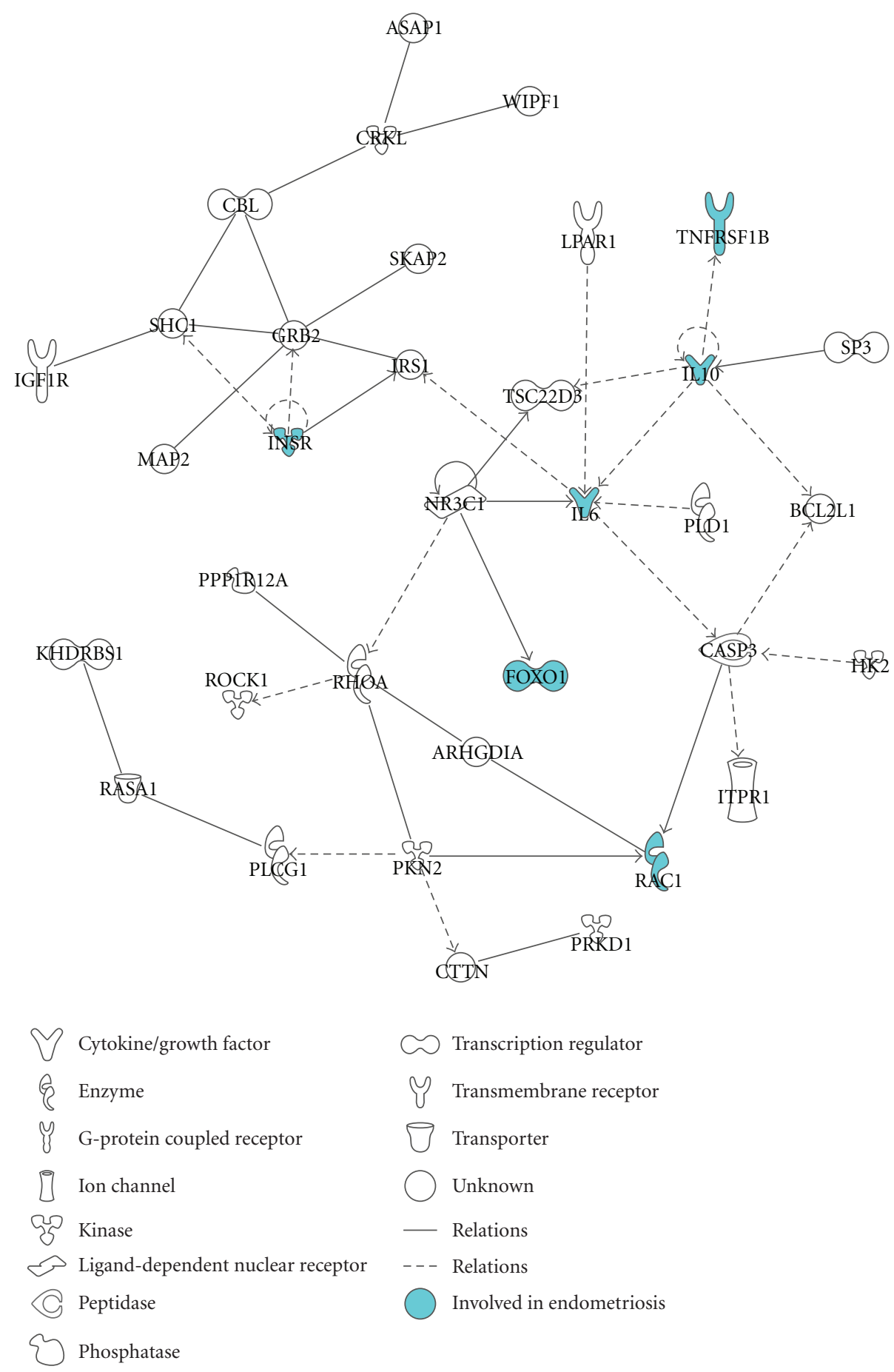

FIGURE 3: Functional analysis of the predicted targets of miR-182, miR-200a, miR-200b, miR-200c, and miR-202 identified by Pictar and Targetscan: graphical representation of one of the network $(P$-value $=10 \mathrm{E}-37$, focus molecules $=35)$ identified by IPA analysis of the predicted targets of the miRNAs whose differential expression in eutopic and ectopic endometrium was validated by real-time RT-PCR. Highlighted are the genes involved in endometriosis according to IPA knowledge base.

of interest with the study. Surgery was scheduled 6 to 12 days after the onset of menses. No patients were receiving hormone therapy at the time of the study or in the previous three months. The patients ranged in age from 24 to 48 years, with an average of 36 years. Endometriomas were removed at laparoscopy by excision of the entire cyst wall by stripping technique, preserving normal ovarian tissue. Hysteroscopy with directed biopsies, performed to obtain a sample of eutopic endometrium from the same patient, were carried out using a $4 \mathrm{~mm}$ Bettocchi Hysteroscope System with a 


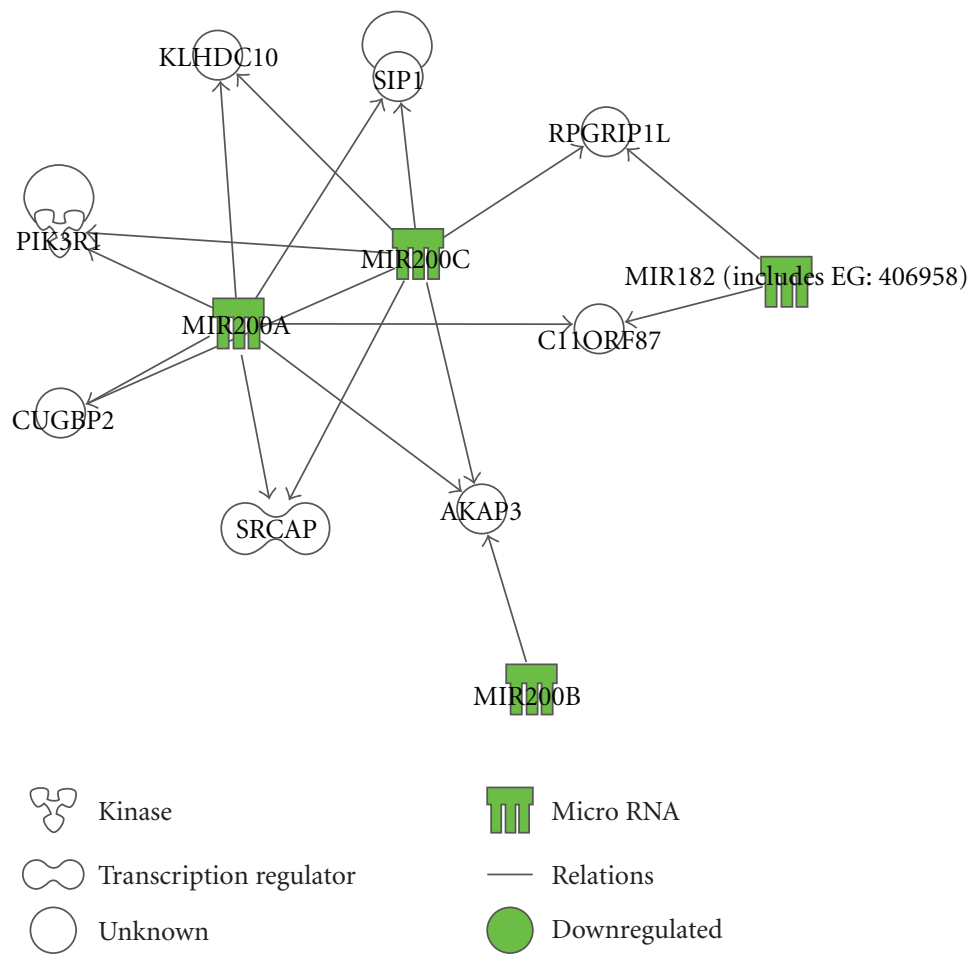

FIGURE 4: Functional analysis of the predicted targets of miR-182, miR-200a, miR-200b, miR-200c, and miR-202 identified by Argonaute2: graphical representation of the network identified by IPA analysis of the miRNAs and their predicted targets using the database generated by Argonaute2 algorithm $(P$-value $=10 \mathrm{E}-14$, focus molecules $=4)$.

5 Fr operative channel (Karl Stortz GmbH \& Co., Tuttlingen, Germany). Laparoscopy and hysteroscopy procedures were performed during the same surgical intervention. Freshly recovered tissues were rinsed in saline solution and divided in two parts. One half of the tissue was immediately snapfrozen and kept in liquid nitrogen for further processing, while the other was sent to the pathology laboratory. The endometriomas of 9 patients were classified as moderate, while 7 were classified as severe according to the ASRM guidelines [39].

2.2. RNA Isolation. Total RNA was extracted from tissues with the miRNeasy kit (Qiagen, Valencia, CA, USA) according to the manufacturer's protocol and quantified by QuantiT RNA Assay Kit with Qubit Fluorometer (Invitrogen, Carlsbad, CA, USA).

2.3. MicroRNA Microarray Assay and Analysis. Microarray assay was performed using a service provider (LC Sciences). Ten $\mu \mathrm{g}$ of total RNA from eutopic and ectopic endometrium obtained from three patients were size fractionated using a YM-100 Microcon centrifugal filter (Millipore) and the small RNAs (<300 nt) isolated were $3^{\prime}$-extended with a poly(A) tail using poly (A) polymerase. An oligonucleotide tag was then ligated to the poly(A) tail for later fluorescent dye staining; two different tags were used for the two RNA samples in dualsample experiments. Hybridization was performed overnight on a $\mu$ Paraflo microfluidic chip using a microcirculation pump (Atactic Technologies) [40, 41]. On the microfluidic chip, each detection probe consisted of a chemically modified nucleotide coding segment complementary to target 475 mature human miRNA probes (Sanger miRBase sequence database 9.1) or other RNAs for control and a spacer segment of polyethylene glycol to extend the coding segment away from the substrate. The detection probes were made by in situ synthesis using PGR (photogenerated reagent) chemistry. The hybridization melting temperatures were balanced by chemical modifications of the detection probes. Hybridization used $100 \mu \mathrm{L}$ 6xSSPE buffer $(0.90 \mathrm{M} \mathrm{NaCl}$, $60 \mathrm{mM} \mathrm{Na}_{2} \mathrm{HPO}_{4}, 6 \mathrm{mM}$ EDTA, pH 6.8) containing $25 \%$ formamide at $34^{\circ} \mathrm{C}$. After RNA hybridization, tag-conjugating $\mathrm{Cy} 3$ and $\mathrm{Cy} 5$ dyes were circulated through the microfluidic chip for dye staining. Fluorescence images were collected using a laser scanner (GenePix 4000B, Molecular Device) and digitized using Array-Pro image analysis software (Media Cybernetics). Data from miRNA microarray were analyzed by the service provider first subtracting the background and then normalizing the signals using an LOWESS filter (Locally weighted Regression) [42]. The ratio of the two sets of detected signals ( $\log 2$ transformed, balanced) and $P$ values of the $t$-test were calculated; differentially detected signals were those with less than $.01 P$-values. Multiple sample analysis involved normalization, data adjustment, $t$ test, and clustering. Normalization was carried out using a cyclic LOWESS. Data adjustment included data filtering, Log2 transformation, and normalization. The $t$-test was performed between "control" and "test" sample groups 


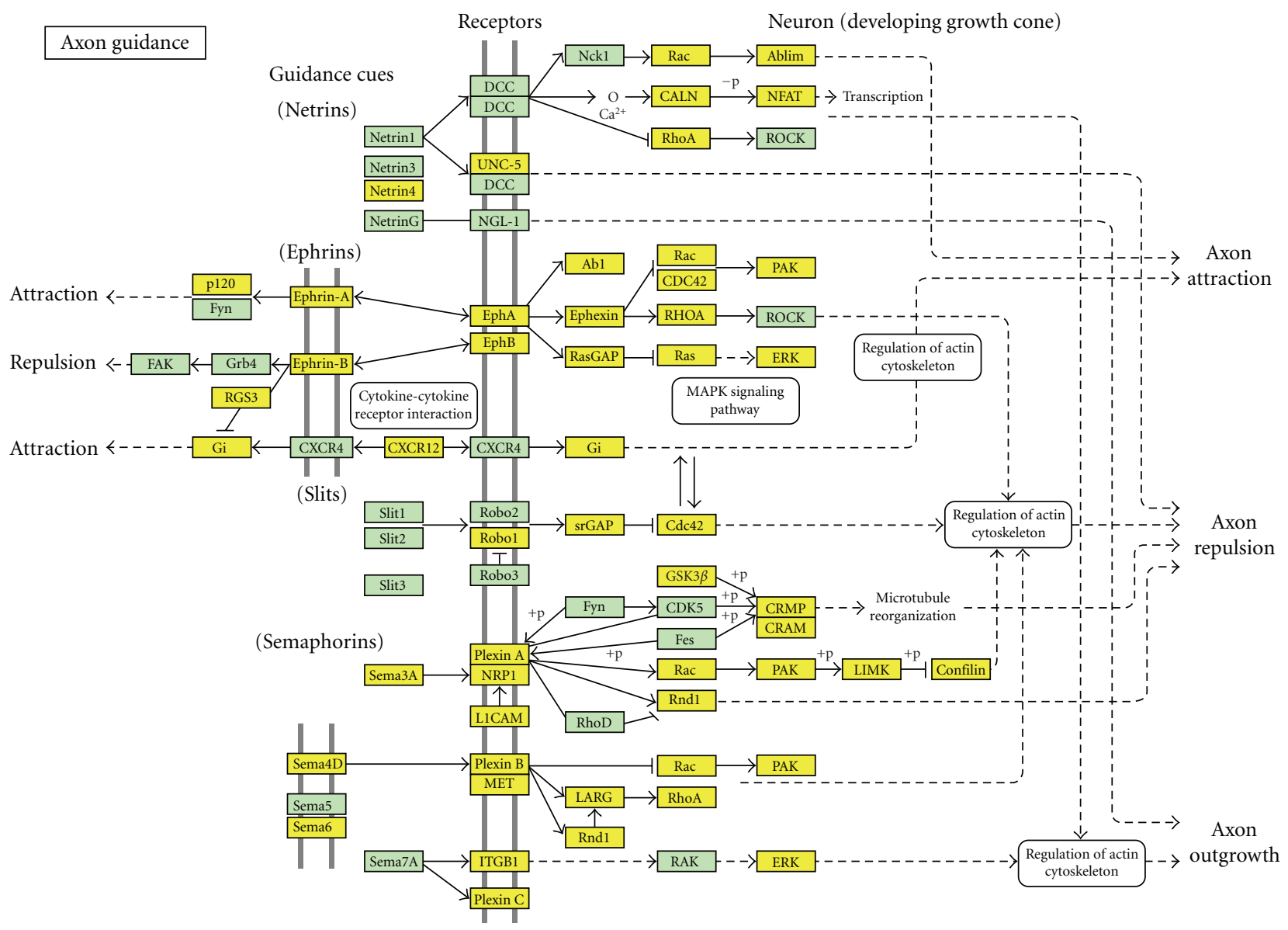

FIGURE 5: The axon guidance pathway identified by Pathway-Express analysis. Pathway-Express analysis performed on the predicted targets of the 50 differentially expressed miRNAs identified, among the most significant KEGG pathways predicted to be relevant for endometriosis, the axon guidance pathway. In yellow are the predicted targets of the differentially expressed miRNAs.

[43]. $T$-values were calculated for each miRNA, and $P$ values were computed from the theoretical $t$-distribution. miRNAs with $P$-values $<.01$ were selected for cluster analysis. The clustering was done using hierarchical method and was performed with average linkage and Euclidean distance metric [44] using TIGR MultiExperiment Viewer (http://www.tm4.org/mev.html).

2.4. Reverse Transcription and Real-Time PCR. Real-time reverse transcription-polymerase chain reaction (real-time RT-PCR) was performed to confirm the differential expression of selected miRNAs, identified as differentially expressed by miRNA microarray, in paired samples from other 13 patients. TaqMan MicroRNA RT Kit (Applied Biosystems, Foster City, CA) was used for reverse transcription. Real-time RT-PCR reactions were carried out with a 7300 Real-Time PCR System (Applied Biosystems) according to the protocol provided by the supplier, using the TaqMan Universal PCR Master Mix No AmpErase UNG and the following TaqMan MicroRNA Assays: hsa-miR-200a, hsa-miR-200b, hsa-miR200c, hsa-miR-182, hsa-miR-202, and U18 as endogenous control.
Data from real-time RT-PCR experiments are presented as the mean \pm SEM. The variation among groups was compared by means of nonparametric Wilcoxon and MannWhitney $U$ tests. Statistical significance was assumed for $P$ values $<.05$. Statistical analysis was performed with SPSS for Windows version 15.0 (SPSS; Chicago, IL).

\section{Results and Discussion}

3.1. MicroRNAs Differentially Expressed in Eutopic and Ectopic Endometrial Tissue. In the present study, we used miRNA microarray technology to identify the pattern of miRNAs in paired eutopic/ectopic endometrium from the same patients, thus avoiding the variables attributable to heterogeneous genetic background between individuals and the effects of estrogenic stimulation during different phases of the menstrual cycle. Moreover, we considered the whole endometrial and endometriotic tissues in order to preserve the contribution of all the components of the tissues, including vascular and immune system components and to avoid potential changes in gene and miRNA expression due to cell isolation and manipulation. 


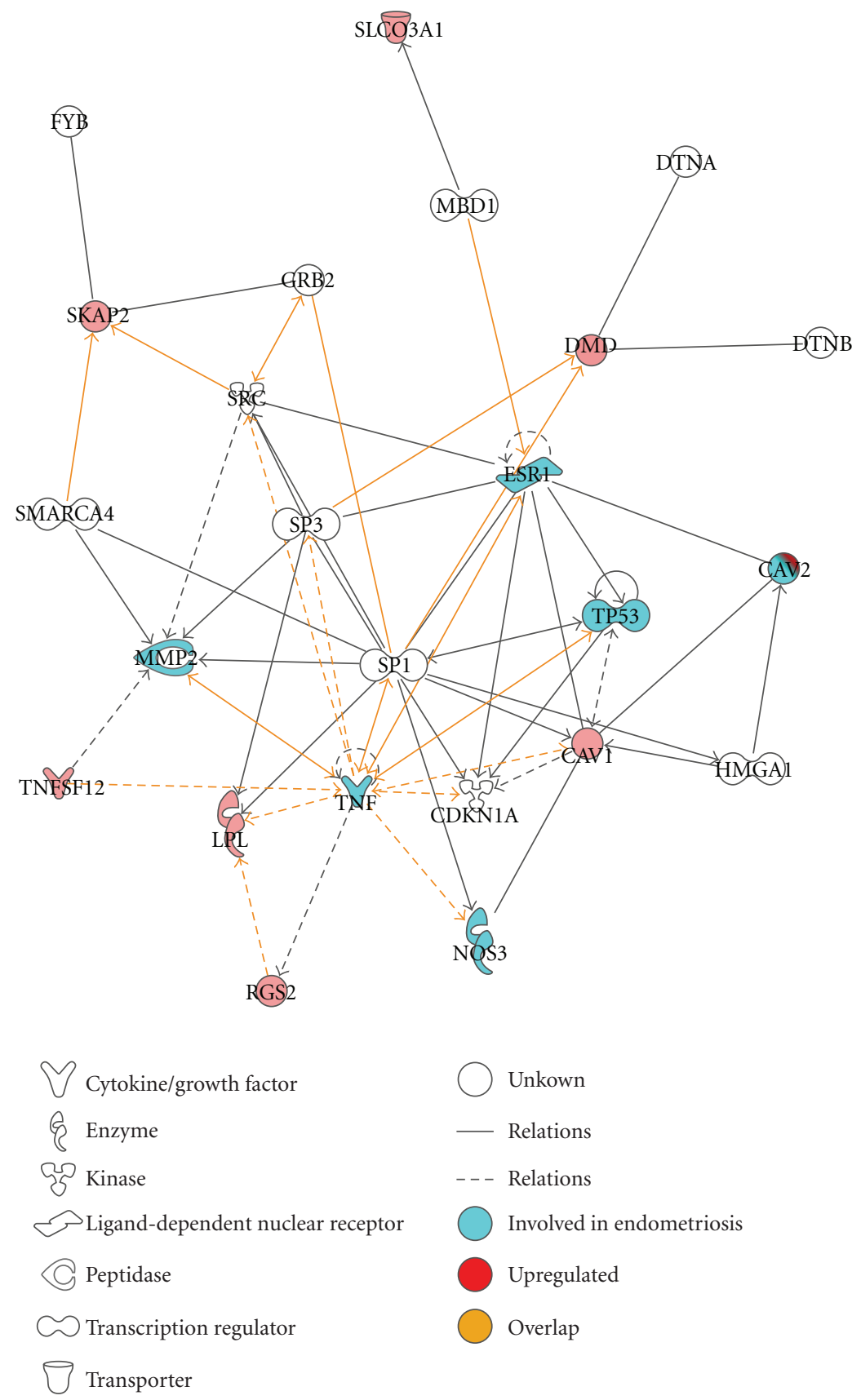

FIGURE 6: Functional analysis of the differentially regulated genes common in ovarian and peritoneal endometriosis that are predicted targets of the 50 miRNAs: Graphical representation of the overlap of the networks identified by IPA with, highlighted are the genes involved in endometriosis according to IPA knowledge base.

Microarray technology has allowed a global analysis of all miRNAs differentially expressed in ectopic versus eutopic endometrium. The initial analysis of miRNA expression in ectopic endometrium compared with eutopic endometrium of three patient samples generated a list of 84 miRNAs significantly differentially expressed $(P$-values $<.01)$. The 50 miRNAs for which the expression value in ectopic endometrium was at least twofold higher or lower than in eutopic endometrium are listed in Table 1.
3.2. Real Time RT-PCR Analysis of miRNA Expression. In order to confirm the results obtained with miRNA microarray, the expression analyses of 5 selected miRNAs was carried out by real-time RT-PCR on specimens from other 13 patients. These 5 miRNAs, namely, hsa-miR-200a, hsamiR-200b, hsa-miR-200c, hsa-miR-182, and hsa-miR-202, were selected because their expression resulted to be highly altered in ectopic endometrium compared with the matched eutopic tissue. We verified the differential expression of the 
TABLE 2: Molecular networks constituted by the predicted miRNA targets. IPA analysis was performed in order to identify the molecular pathways and functions to which the predicted targets of the differentially expressed miRNAs belong. The networks are generated on the basis of the published literature and ranked by the $P$-value calculated by Fisher's exact Test. The biological processes in which the targets are involved are determined by IPA using the GOstat application $P<.01$.

\begin{tabular}{|c|c|c|c|c|}
\hline ID & Molecules in network & $P$-value & $\begin{array}{c}\text { Focus } \\
\text { molecules }\end{array}$ & Top functions \\
\hline 1 & $\begin{array}{l}\text { ACTR1A, ADM, APP, BICD2, } \\
\text { CABP7, CELSR1, CPSF6, DAG1, } \\
\text { ELAVL1, EPHA2, GCH1, GNA13, } \\
\text { HIRA, HLX, HNRNPH1, } \\
\text { HNRNPM, IFNG, IRF2, } \\
\text { KHDRBS1, LARGE, MAPT, } \\
\text { MTMR3, MTMR4, MYH9, } \\
\text { PCSK2, PLCG1, PTGS2, RASA1, } \\
\text { SBF1, SOCS1, SOCS2, STAT6, } \\
\text { TNPO1, TNPO2, TRIB2 }\end{array}$ & $10 \mathrm{E}-21$ & 35 & $\begin{array}{l}\text { Cellular Development, Skeletal } \\
\text { and Muscular Disorders, } \\
\text { Organismal Development }\end{array}$ \\
\hline 2 & $\begin{array}{l}\text { AEBP2, ATAD2, C1QTNF6, } \\
\text { CAV1, CAV2, CBX1, CCND1, } \\
\text { CREB1, DAB2IP, DDIT4, } \\
\text { DNMT1, DNMT3A, DNMT3B, } \\
\text { DUSP9, EED, ESR1, EZH2, } \\
\text { FOLR1, HSPA13, KAT2B, LEP, } \\
\text { MED1, MED14, NCOA2, NCOA3, } \\
\text { NCOA4, NOTCH3, PHF1, } \\
\text { PNRC1, PRLR, RBBP7, RBM9, } \\
\text { SIRT1, THRA (includes EG:7067), } \\
\text { TMOD1 }\end{array}$ & $10 \mathrm{E}-21$ & 35 & $\begin{array}{l}\text { Gene Expression, Cellular } \\
\text { Growth and Proliferation, } \\
\text { Developmental Disorder }\end{array}$ \\
\hline 3 & $\begin{array}{l}\text { AKAP13, BCL2L11, CCNE2, } \\
\text { CDK6, CDKN1A, CDKN1B, } \\
\text { CTGF, CTSB, CUGBP1, DUSP1, } \\
\text { E2F1, ESRRG, ETS1, FHL2, FLI1, } \\
\text { FOXO1, FOXO3, FOXO4, IGFBP3, } \\
\text { IP6K3, JAG1, KRAS, MCF2, } \\
\text { NR3C1, PRKD3, RB1CC1, SGK1, } \\
\text { SMAD3, SP1, SPHK2, TCF7L2 } \\
\text { (includes EG:6934), TGFBR1, } \\
\text { TIMP3, TOPBP1, TSPYL2 }\end{array}$ & $10 \mathrm{E}-21$ & 35 & $\begin{array}{l}\text { Cellular Growth and } \\
\text { Proliferation, Cellular } \\
\text { Development, Cancer }\end{array}$ \\
\hline 4 & $\begin{array}{l}\text { ADAM12, BCL2, CITED2, } \\
\text { EGLN1, FGF9, FRAP1, GATA3, } \\
\text { GNAI2, HIF1A, HSPD1, IGF1R, } \\
\text { IKBKB, ITGA9, JUNB, KPNA1, } \\
\text { KPNB1, MAP2K3, MAP2K5, } \\
\text { MAP3K7, MAP3K7IP2, PIAS3, } \\
\text { PPM1B, PRKCE, PTEN, PTPN1, } \\
\text { RPS6KB1, SKI, SMAD7, SNAI1, } \\
\text { SOCS3, SP2, STAT3, UBR5, WT1, } \\
\text { ZEB1 }\end{array}$ & $10 \mathrm{E}-21$ & 35 & $\begin{array}{l}\text { Cellular Growth and } \\
\text { Proliferation, Cellular } \\
\text { Movement, Cell Cycle }\end{array}$ \\
\hline 5 & $\begin{array}{l}\text { ANP32A, ATP2A2, CD69, } \\
\text { CDK5R1, COL1A1, COL1A2, } \\
\text { CREM, DDR1, DLL4, E2F3, } \\
\text { EGR1, FBXW7, FLT1, HDAC4, } \\
\text { IL2, IL18BP, LPL, NDRG1, } \\
\text { NOTCH1, PHC1, PHC2, POLA1, } \\
\text { PPARA, RANBP2, RB1, RYBP, } \\
\text { SHC1, SP3, SP4, TRAM2 } \\
\text { (includes EG:9697), XPO1, YBX1, } \\
\text { YY1, ZBTB10, ZBTB7B }\end{array}$ & $10 \mathrm{E}-21$ & 35 & $\begin{array}{l}\text { Organismal Injury and } \\
\text { Abnormalities, Cardiovascular } \\
\text { Disease, Cellular Development }\end{array}$ \\
\hline
\end{tabular}


Table 2: Continued.

\begin{tabular}{|c|c|c|c|c|}
\hline ID & Molecules in network & $P$-value & $\begin{array}{c}\text { Focus } \\
\text { molecules }\end{array}$ & Top functions \\
\hline 6 & $\begin{array}{l}\text { ARNT, BACH1, BCL2L12, } \\
\text { BRCA1, CLOCK, CREBBP, } \\
\text { CYP1B1, DDX5, EP300, EPAS1, } \\
\text { ERBB4, EREG, GABPA, } \\
\text { GADD45A, HBEGF, HOXA13, } \\
\text { HOXB6, LEF1, MAB21L1, MAX, } \\
\text { NCAM1, NFYA, NPAS2, OXTR, } \\
\text { PIN1, PPARG, PPP2CA, PTGER4, } \\
\text { RBBP8 (includes EG:5932), } \\
\text { RUNX1, SDC1, SLC1A2, TGFA, } \\
\text { TRERF1, WNT5A }\end{array}$ & $10 \mathrm{E}-21$ & 35 & $\begin{array}{l}\text { Gene Expression, Cancer, } \\
\text { Genetic Disorder }\end{array}$ \\
\hline 7 & $\begin{array}{l}\text { ACTB, ARID1A, ARID1B, } \\
\text { ARID4A, ARID4B, BTG2, CLIP1, } \\
\text { DR1, ETS2, EWSR1, GTF2B, } \\
\text { HOXA9, PFN1, RARB, RBL1, } \\
\text { RBL2, SAP30, SAP130, SFPQ, } \\
\text { SIN3A, SMARCA2, SMARCA4, } \\
\text { SMARCB1, SMARCC1, } \\
\text { SMARCC2 (includes EG:6601), } \\
\text { SNIP1, SUMO1, TACC2, TAF4, } \\
\text { TAF5, TAF12, TBP, TDG, TOP1, } \\
\text { XPO6 }\end{array}$ & $10 \mathrm{E}-21$ & 35 & $\begin{array}{l}\text { Gene Expression, Cellular } \\
\text { Assembly and Organization, } \\
\text { Cellular Compromise }\end{array}$ \\
\hline 8 & $\begin{array}{l}\text { ARHGDIA, BTRC, CASP3, CD4, } \\
\text { CDC42, CLTC, CTTN, CXCL12, } \\
\text { DIABLO, ELK1, ELK3, EZR, F3, } \\
\text { FOS, FOSB, GLI3, GSK3B, } \\
\text { HNRNPA1, HNRNPC, IL1A, } \\
\text { ITPR1, JUND, MAP1B, MCL1, } \\
\text { OCRL, PAK1, PGM1, PRKCI, } \\
\text { PRKD1, PTX3, RABEP1, RAC1, } \\
\text { SEMA3A, SRF, STK4 }\end{array}$ & $10 \mathrm{E}-21$ & 35 & $\begin{array}{l}\text { Cell Death, Cancer, Cellular } \\
\text { Assembly and Organization }\end{array}$ \\
\hline 9 & $\begin{array}{l}\text { CD47, CSF1, CSF1R, CSK, } \\
\text { EPHA4, FASLG, FGF1, FN1, } \\
\text { FOXP1, GRB2, IRS2, ITGA5, } \\
\text { ITGA6, ITGA10, ITGA11, ITGAV, } \\
\text { ITGB1, ITGB3, JAK2, KCNA3, } \\
\text { MAP2K1, MAP2K4, MAPK1, } \\
\text { MET, MITF, NFAT5, PDGFB, } \\
\text { PDGFRB, PLXNB1, RAB21, } \\
\text { SERPINE1, TNFRSF1A, } \\
\text { TNFSF11, TRIB1, YES1 }\end{array}$ & $10 \mathrm{E}-21$ & 35 & $\begin{array}{l}\text { Cellular Growth and } \\
\text { Proliferation, Cell-mediated } \\
\text { Immune Response, Cellular } \\
\text { Movement }\end{array}$ \\
\hline 10 & $\begin{array}{l}\text { ACTR3, AR, ARHGEF7, ASAP1, } \\
\text { CRKL, DYRK1A, ESR1, GDI1, } \\
\text { KLF2, LMOD1, LRRK1, MRAS, } \\
\text { NCK1, PFTK1, PLS3, POMT2, } \\
\text { TEAD3, TRIP10, WAS, WEE1, } \\
\text { WIPF1, ZMIZ1 }\end{array}$ & $10 \mathrm{E}-9$ & 19 & $\begin{array}{l}\text { Cellular Assembly and } \\
\text { Organization, Skeletal and } \\
\text { Muscular System Development } \\
\text { and Function, Cancer }\end{array}$ \\
\hline 11 & $\begin{array}{l}\text { AKAP12, AMOTL2, ARL6IP1, } \\
\text { ATM, BRCA1, CDC6, CHEK2, } \\
\text { E2F1, FKBP3, HS3ST1, LATS2, } \\
\text { LBR, MBNL2, MTDH, PPM1D, } \\
\text { PPP1R13B, SCN3B, SH3BP4, } \\
\text { TP53, TRIO, VCAN }\end{array}$ & $10 \mathrm{E}-7$ & 17 & $\begin{array}{l}\text { Cancer, Genetic Disorder, } \\
\text { Reproductive System Disease }\end{array}$ \\
\hline 12 & $\begin{array}{l}\text { ANK3, CREB5, DEDD, FRK, } \\
\text { GPRC5A, KCNK2, KRT18, } \\
\text { MPZL2, MYCBP2, MYO1B, NRK, } \\
\text { RAB22A, SPAG9, ZNF217 }\end{array}$ & $10 \mathrm{E}-7$ & 13 & $\begin{array}{l}\text { Cardiovascular Disease, } \\
\text { Cellular Development, Cell } \\
\text { Morphology }\end{array}$ \\
\hline
\end{tabular}


Table 2: Continued.

\begin{tabular}{|c|c|c|c|c|}
\hline ID & Molecules in network & $P$-value & $\begin{array}{c}\text { Focus } \\
\text { molecules }\end{array}$ & Top functions \\
\hline 13 & $\begin{array}{l}\text { ADAM19, CADM1, CBFA2T3, } \\
\text { CDC42SE1, COL6A3, COL7A1, } \\
\text { DAAM1, ERBB2, FN1, HAS3, } \\
\text { MFAP2, MPHOSPH9, NET1, } \\
\text { PMEPA1, RAP1B, TGFB1, THBS1, } \\
\text { THPO, XYLT1, ZFP36 }\end{array}$ & $10 \mathrm{E}-7$ & 16 & $\begin{array}{l}\text { Cancer, Cellular Growth and } \\
\text { Proliferation, Dermatological } \\
\text { Diseases and Conditions }\end{array}$ \\
\hline 14 & $\begin{array}{l}\text { ATP1B3, CCND1, COL3A1, } \\
\text { COL4A1, COL5A2, CTNNB1, } \\
\text { HOXA1, IGF2R, KLF9, LGALS3, } \\
\text { M6PR, MAP3K10, NANOG, } \\
\text { NPTX1, NRF1, NRIP1, PTPRC, } \\
\text { PTTG1, RB1, SPTBN2, TCF7L2 } \\
\text { (includes EG:6934), THRB } \\
\text { (includes EG:7068), TP53 }\end{array}$ & $10 \mathrm{E}-6$ & 17 & $\begin{array}{l}\text { Organismal Development, } \\
\text { Cancer, Cell Cycle }\end{array}$ \\
\hline 15 & $\begin{array}{l}\text { ALDH1A3, COLQ, DUSP10, } \\
\text { EIF4B, GPD2, HSPE1, IL6, IL13, } \\
\text { IL1B, MMD, NR4A3, NUAK1, } \\
\text { PTPN12, RND3, ROBO1, } \\
\text { SEMA3C, SLC7A1, STAC, TNF, } \\
\text { TNFSF10, TUB }\end{array}$ & $10 \mathrm{E}-6$ & 16 & $\begin{array}{l}\text { Small Molecule Biochemistry, } \\
\text { Skeletal and Muscular System } \\
\text { Development and Function, } \\
\text { Cell-To-Cell Signaling and } \\
\text { Interaction }\end{array}$ \\
\hline 16 & $\begin{array}{l}\text { ACSL3, ASXL1, EGR3, JMJD1C, } \\
\text { PLK2, PTP4A1, RRM2, RRM1 } \\
\text { (includes EG:6240), RRM2B, } \\
\text { SEL1L, SFRS3, SLC2A1, SMURF2, } \\
\text { SON, STRN3, TNF, TP53, UBE2B, } \\
\text { ZFP36L1 }\end{array}$ & $10 \mathrm{E}-6$ & 15 & $\begin{array}{l}\text { Nucleic Acid Metabolism, Small } \\
\text { Molecule Biochemistry, Genetic } \\
\text { Disorder }\end{array}$ \\
\hline 17 & $\begin{array}{l}\text { CCND1, CCNT1, CCNT2, CDK9, } \\
\text { CDKN1A, DNAJB9, FBXW11, } \\
\text { GLI1, GLI2, GNAO1, GTF2F2, } \\
\text { HSPA5, HTATSF1, ID2, JAG2, } \\
\text { MDFIC, MXI1, MYCN, NPM1 } \\
\text { (includes EG:4869), POLR2A, } \\
\text { POLR2C, RB1, RPS6KA1, RXRA, } \\
\text { SFRS1, SUPT5H, SUPT6H, } \\
\text { TCERG1, TGFB1, TP53, ULK1 }\end{array}$ & $10 \mathrm{E}-6$ & 20 & $\begin{array}{l}\text { Gene Expression, Cellular } \\
\text { Development, Cell Cycle }\end{array}$ \\
\hline 18 & $\begin{array}{l}\text { APBB2, BECN1, CAD, CDKN1A, } \\
\text { CFL1, E2F5, ESR1, FANCA, } \\
\text { FANCC, FGF7, GFI1, GJA1, } \\
\text { GORASP2, HSP90AA1, LIMK1, } \\
\text { MAX, MYC, PCBP2, PERP, } \\
\text { PTBP1, SPTAN1, TERT, TMSB4X, } \\
\text { TP53, XBP1 }\end{array}$ & $10 \mathrm{E}-5$ & 17 & $\begin{array}{l}\text { Cell Cycle, Connective Tissue } \\
\text { Development and Function, } \\
\text { Cellular Compromise }\end{array}$ \\
\hline 19 & $\begin{array}{l}\text { AP3M1, BCL6, CCND1, CREBL2, } \\
\text { ENC1, FOXA1, FTH1, HNF1A, } \\
\text { HNMT, MTA3, MUC4, NCOR1, } \\
\text { NCOR2, NFE2L2, NFYC, NR5A2, } \\
\text { SNX17, SSTR1, TFR2, TFRC, } \\
\text { TMOD2 }\end{array}$ & $10 \mathrm{E}-5$ & 15 & $\begin{array}{l}\text { Cancer, Gene Expression, Drug } \\
\text { Metabolism }\end{array}$ \\
\hline 20 & $\begin{array}{l}\text { ACTB, ACTL6A, CCNT1, CD9, } \\
\text { CTCF, DMAP1, EMD, EPC1, } \\
\text { ESR1, HABP2, HNRNPA1, } \\
\text { HNRNPF, HNRNPK, HSP90AA1, } \\
\text { LEMD3, MKNK2, MORF4L1, } \\
\text { MYC, PCBP1 (includes EG:5093), } \\
\text { SYNE2, TBP, THOC4, TNPO1, } \\
\text { TRRAP, U2AF1, WNT1, WNT2B, } \\
\text { YY1, ZBTB33 }\end{array}$ & $10 \mathrm{E}-5$ & 18 & $\begin{array}{l}\text { Gene Expression, Cancer, } \\
\text { Reproductive System Disease }\end{array}$ \\
\hline
\end{tabular}


Table 2: Continued.

\begin{tabular}{|c|c|c|c|c|}
\hline ID & Molecules in network & $P$-value & $\begin{array}{c}\text { Focus } \\
\text { molecules }\end{array}$ & Top functions \\
\hline 21 & $\begin{array}{l}\text { BEX2, CDH1, CDH2, CDH11, } \\
\text { CTNNA2, CTNNB1, CTNND2, } \\
\text { DIO2, ELAVL1, EPHB3, ERBB2, } \\
\text { ESR1, F13A1, HNRNPD, ILF3, } \\
\text { IRS1, JUP, KHSRP, LDB1, LMO2, } \\
\text { NHLH2, PIK3R1, PKD1, } \\
\text { PPP3CA, PTCH1, PTPRF, TCF7L2 } \\
\text { (includes EG:6934), TIAL1, TP53, } \\
\text { TSC22D1, ZNF346 }\end{array}$ & $10 \mathrm{E}-4$ & 18 & $\begin{array}{l}\text { Cell-To-Cell Signaling and } \\
\text { Interaction, Cancer, Cellular } \\
\text { Growth and Proliferation }\end{array}$ \\
\hline 22 & $\begin{array}{l}\text { ACIN1, AP2A1, BRD2, COIL, } \\
\text { EIF4A1, EIF4G3, ICMT, LMO7, } \\
\text { MAP7, NME1, PA2G4, PABPC1, } \\
\text { PABPN1, PAIP1, PAIP2, PAPOLG, } \\
\text { PNN, RNGTT, RNPS1, SAP18, } \\
\text { SFRS11, TALDO1, TRA2B, } \\
\text { ZNF143 }\end{array}$ & $10 \mathrm{E}-4$ & 15 & $\begin{array}{l}\text { RNA Post-Transcriptional } \\
\text { Modification, Protein Synthesis, } \\
\text { Gene Expression }\end{array}$ \\
\hline 23 & $\begin{array}{l}\text { ADAM9, ADAM10, BMP7, CCL2, } \\
\text { CCL5, CDH1, COL18A1, } \\
\text { CTNNB1, DICER1, EGF, EGFR, } \\
\text { EPS15, ERBB2, ETV1, GRB2, } \\
\text { HGS, IL8, L1CAM, LPAR1, LPP } \\
\text { (includes EG:4026), MAP3K14, } \\
\text { NKRF, RALA, RELA (includes } \\
\text { EG:5970), SHC1, SMAD5, SPG20, } \\
\text { SRC, TBK1, TERT, TJP1, } \\
\text { TMEM55A, TMEM55B, TNF }\end{array}$ & $10 \mathrm{E}-4$ & 19 & $\begin{array}{l}\text { Cell-To-Cell Signaling and } \\
\text { Interaction, Tissue } \\
\text { Development, Cancer }\end{array}$ \\
\hline 24 & $\begin{array}{l}\text { ALOX15, BZW2, CCL3, CHST2, } \\
\text { DHCR24, FCER2, GAS7, GATA6, } \\
\text { IGHE, IL4, IL8, IL13, MTSS1, } \\
\text { NHLH1, NOS2, NOTCH2, } \\
\text { PDGFC, PHLDA1, PLXNC1, } \\
\text { RIN2, SORT1, ST8SIA4 }\end{array}$ & $10 \mathrm{E}-4$ & 14 & $\begin{array}{l}\text { Genetic Disorder, } \\
\text { Inflammatory Disease, } \\
\text { Respiratory Disease }\end{array}$ \\
\hline 25 & $\begin{array}{l}\text { CAND1, CCND2, CDC5L, } \\
\text { CDKN1B, CUL1, CUL2, CUL3, } \\
\text { DNTT, FBXL3, FBXW2, GPR37, } \\
\text { PARK2, PITX2, PLRG1, PMS1, } \\
\text { PRCC, PRPF19, PSMA2, PSMC1, } \\
\text { PSMC5, RAD23B, RBX1 (includes } \\
\text { EG:9978), SFRS2, SKP1, SKP2, } \\
\text { TCEB1, VHL }\end{array}$ & $10 \mathrm{E}-4$ & 16 & $\begin{array}{l}\text { Post-Translational } \\
\text { Modification, Cancer, } \\
\text { Immunological Disease }\end{array}$ \\
\hline 26 & $\begin{array}{l}\text { AMOT, B4GALT5, BTG3, CCL2, } \\
\text { CD40, CHMP2B, CLASP1, ETS1, } \\
\text { F3, FOS, HIVEP1, IKBKB, IL2, } \\
\text { IL6, IL15, JAK1, JUN, MAPK1, } \\
\text { MAPK14, MVP, NEFM, NFKB1, } \\
\text { NFKBIA, PLG, PPP2R1B, RAB32, } \\
\text { RELA (includes EG:5970), } \\
\text { RFWD2 (includes EG:64326), } \\
\text { RGS2, SQSTM1, STAT1, STAT3, } \\
\text { TNF, TYK2, ZBTB11 }\end{array}$ & $10 \mathrm{E}-4$ & 19 & $\begin{array}{l}\text { Hematological System } \\
\text { Development and Function, } \\
\text { Cell Death, Cell Cycle }\end{array}$ \\
\hline 27 & $\begin{array}{l}\text { CCNA2, CCNB1, CCNE1, } \\
\text { CCNE2, CD46, CD59, CDK2, } \\
\text { CDKN1C, E2F4, EPHB2, } \\
\text { FBXO32, HDAC9, HIVEP2, } \\
\text { IGFBP3, KLF4, LATS1, LTC4S, } \\
\text { MYB (includes EG:4602), MYBL2, } \\
\text { NDC80, NUMB, PCNA, PLAU, } \\
\text { POLD1, RALBP1, RBL1, RBL2, } \\
\text { RFC4, RFX1, SCD, SPARC, } \\
\text { SUZ12, TGFB1, TGFB3, TNS3 } \\
\end{array}$ & $10 \mathrm{E}-4$ & 19 & $\begin{array}{l}\text { Cell Cycle, Cancer, Cellular } \\
\text { Growth and Proliferation }\end{array}$ \\
\hline
\end{tabular}


Table 2: Continued.

\begin{tabular}{|c|c|c|c|c|}
\hline ID & Molecules in network & $P$-value & $\begin{array}{c}\text { Focus } \\
\text { molecules }\end{array}$ & Top functions \\
\hline 28 & $\begin{array}{l}\text { ABL1, ADRB2, ATP1A1, ATP1A2, } \\
\text { ATP1B1, BCAR1, BCAR3, BCR, } \\
\text { CBL, CRK, DOCK1, FRAP1, FYN, } \\
\text { GATA2, GRK4, ITGA2B (includes } \\
\text { EG:3674), ITGB3, MAPK9, } \\
\text { MGRN1, NEU2, PIAS1, PIK3R1, } \\
\text { PLSCR1, PRKCD, PTK2, } \\
\text { RAPGEF1, RECK, SP3, SRC, } \\
\text { STAT1, TIMP2, TP73, TP53INP1, } \\
\text { TSG101, VPS28 }\end{array}$ & $10 \mathrm{E}-4$ & 19 & $\begin{array}{l}\text { Cell Death, Cellular Movement, } \\
\text { Cellular Growth and } \\
\text { Proliferation }\end{array}$ \\
\hline 29 & $\begin{array}{l}\text { AKAP11, B2M, BHLHE40, } \\
\text { CALD1, CEBPA, CHI3L1, } \\
\text { COL16A1, EDN1, EDNRB, } \\
\text { EIF1AX, EMP1, HMGA1, } \\
\text { HMGCR, HMGCS1, IDI1, } \\
\text { INSIG1, IPO13, KIT, KITLG, LSS, } \\
\text { MMP2, MMP3, NAMPT, NPPB, } \\
\text { PRKCA, PTPN6, RETN, SCARB1, } \\
\text { SERPINB1, SERPINE1, TGFBR2, } \\
\text { TGIF2, TNC, TNF, UBE2I }\end{array}$ & $10 \mathrm{E}-4$ & 19 & $\begin{array}{l}\text { Cancer, Hematological Disease, } \\
\text { Lipid Metabolism }\end{array}$ \\
\hline 30 & $\begin{array}{l}\text { ALOX12B, APOE, ATF7IP, } \\
\text { BCAT2, CAMK2A, CAMK2N1, } \\
\text { CCND3, CDKN1B, CHAF1A, } \\
\text { CRYBB2, DPP4, EFNA5, ESR1, } \\
\text { GSTP1, HBE1, IL4, IL13RA1, } \\
\text { IRF4, KCNK10, MBD1, MBD2, } \\
\text { MBD3 (includes EG:53615), } \\
\text { MECP2, MGMT, NR1H3, NR2F2, } \\
\text { PIP5K3, PRLR, PTPN4, PTPRM, } \\
\text { SETDB1, SLCO3A1, TFF2, } \\
\text { TP53BP2, TSC1 }\end{array}$ & $10 \mathrm{E}-4$ & 19 & $\begin{array}{l}\text { Behavior, Reproductive System } \\
\text { Development and Function, } \\
\text { Neurological Disease }\end{array}$ \\
\hline 31 & $\begin{array}{l}\text { ARHGEF6, BNIP2, CASP8, } \\
\text { CHFR, CPD, CS, ELF1, IFNB1, } \\
\text { IL8, IL16, INS, IRF1, JAK2, } \\
\text { LMTK2, NCF2, NFKBIA, NGFR, } \\
\text { PGAM1, PGK1, PLAGL2, } \\
\text { PPP1CC, PPP1R12B, PRL, STAT1, } \\
\text { TNF, TRADD }\end{array}$ & $10 \mathrm{E}-3$ & 15 & $\begin{array}{l}\text { Immunological Disease, Cell } \\
\text { Death, Hematological Disease }\end{array}$ \\
\hline 32 & $\begin{array}{l}\text { ACHE, AGT, APP, ATP2B1, } \\
\text { BACE1, BIK, BMP2, BTG2, } \\
\text { CCL20, CD40LG, CDH1, CXCL2, } \\
\text { CYCS (includes EG:54205), } \\
\text { EFNA1, EIF4E, EIF4EBP1, GCLC, } \\
\text { ITM2B, JUN, LAMP3, LYN, } \\
\text { MYO6, PDK4, PPARD, PSEN1, } \\
\text { PTGS2, PXN, SMAD1, SMPD2, } \\
\text { SOX9, TNF, TNFAIP2, TNFSF10, } \\
\text { TRPV6, VCL }\end{array}$ & $10 \mathrm{E}-3$ & 18 & $\begin{array}{l}\text { Cell Death, Cancer, } \\
\text { Cell-To-Cell Signaling and } \\
\text { Interaction }\end{array}$ \\
\hline 33 & $\begin{array}{l}\text { AHR, ANP32B, ATM, BIRC3, } \\
\text { BTG2, CAMK2G, CEBPE, CLU, } \\
\text { ELAVL1, ERCC1, GDF11, H2AFX, } \\
\text { HDAC3, HNRNPD, HNRNPU, } \\
\text { HOXA5, ILF3, NEDD8, NUP153, } \\
\text { RAD50, RARA, RARB, RARG, } \\
\text { TBX3, TERF2, TERF2IP, TIA1, } \\
\text { TIAL1, TINF2, TP53, TPR, XPO1, } \\
\text { XRCC5, XRCC6, YAP1 }\end{array}$ & $10 \mathrm{E}-3$ & 18 & $\begin{array}{l}\text { Cell Cycle, DNA Replication, } \\
\text { Recombination, and Repair, } \\
\text { Cell Death }\end{array}$ \\
\hline
\end{tabular}


Table 2: Continued.

\begin{tabular}{|c|c|c|c|c|}
\hline ID & Molecules in network & $P$-value & $\begin{array}{c}\text { Focus } \\
\text { molecules }\end{array}$ & Top functions \\
\hline 34 & $\begin{array}{l}\text { ADH5 (includes EG:128), ASH2L, } \\
\text { ATP6V0C, C16ORF53, CHRNA5, } \\
\text { CSNK2A1, CSNK2B, DPY30, } \\
\text { EDA, ETV4, HCFC1, HDAC1, } \\
\text { HIST2H4A, MIER1, MLL3, } \\
\text { MLL4, MRC2, NCOA6, OGT } \\
\text { (includes EG:8473), PAXIP1, } \\
\text { PKNOX1, PLAU, PLAUR, } \\
\text { POU2F1, RBBP5, SIN3A, SP1, } \\
\text { SP3, SSRP1, SUB1, SUPT16H, } \\
\text { TEAD1, TRIM63, WDR5, } \\
\text { ZBTB7A }\end{array}$ & $10 \mathrm{E}-3$ & 18 & $\begin{array}{l}\text { Gene Expression, Cell } \\
\text { Morphology, Reproductive } \\
\text { System Development and } \\
\text { Function }\end{array}$ \\
\hline 35 & $\begin{array}{l}\text { APLN, BID, CASP2, CFLAR, } \\
\text { CXCL13, CYCS (includes } \\
\text { EG:54205), DIABLO, EIF2S1, } \\
\text { EIF4B, EIF4E, EIF4EBP1, EIF4G1, } \\
\text { IL21, IL1RN, INHA, INHBA, } \\
\text { INHBB, JAK1, LEFTY1, MCL1, } \\
\text { NFKB2, P4HA1, PPP1R15A } \\
\text { (includes EG:23645), PRDM1, } \\
\text { SATB1, SERPINB2, SOCS1, } \\
\text { SOCS3, SUV39H1, TAL1, TLR4, } \\
\text { TNF, TNFSF10, USF1, USF2 }\end{array}$ & $10 \mathrm{E}-3$ & 18 & $\begin{array}{l}\text { Protein Synthesis, Cancer, Cell } \\
\text { Death }\end{array}$ \\
\hline 36 & $\begin{array}{l}\text { CEBPB, CSF1, CSF3, EGFR, FGA, } \\
\text { GAB1, GRB2, IL6, IL1A, IL6ST, } \\
\text { IRS1, JAK1, KIF5B, LIFR, LMO4, } \\
\text { LPAR2, MAP2, MED28, NF2, } \\
\text { NFKB1, OSM, OSMR, PIK3C2B, } \\
\text { PLG, POU2F1, POU2F2, PRL, } \\
\text { PTGS2, PTPN11, RNASE1, } \\
\text { RNASE2, SKAP2, STAT3, TLR9, } \\
\text { VIP }\end{array}$ & $10 \mathrm{E}-3$ & 18 & $\begin{array}{l}\text { Cellular Development, Cellular } \\
\text { Growth and Proliferation, } \\
\text { Cancer }\end{array}$ \\
\hline 37 & $\begin{array}{l}\text { AOF2, BAZ1A, BAZ1B, } \\
\text { CACNA1C, CDYL, CHRAC1, } \\
\text { CTBP1, CTBP2, EHMT1, } \\
\text { EHMT2, GATA4, HAND1, } \\
\text { HAND2, HDAC2, HMG20B, } \\
\text { KCNJ3, MEF2C, MYOCD, } \\
\text { PDS5A, PHF21A, POLE3, RAD21, } \\
\text { RBBP4, RCOR1, RREB1, SCN5A, } \\
\text { SFRP1, SMARCA1, SMARCA5, } \\
\text { SMC3, SMC1A, STAG1, STAG2, } \\
\text { WIZ, ZEB2 }\end{array}$ & $10 \mathrm{E}-3$ & 18 & $\begin{array}{l}\text { Cell Cycle, DNA Replication, } \\
\text { Recombination, and Repair, } \\
\text { Gene Expression }\end{array}$ \\
\hline 38 & $\begin{array}{l}\text { AKAP1, API5, ARHGEF12, CFTR, } \\
\text { COL18A1, F2, F2R, FGF2, FGFR1, } \\
\text { IL1B, IQGAP2, MPRIP, } \\
\text { PPP1R12A, PRKAR2B, PRKG1, } \\
\text { PTGER3, RHOA, SH3GLB1, } \\
\text { SH3GLB2 (includes EG:56904), } \\
\text { SLC9A3R1, SRC, STX1A, VCP }\end{array}$ & $10 \mathrm{E}-3$ & 13 & $\begin{array}{l}\text { Cellular Assembly and } \\
\text { Organization, Cell } \\
\text { Morphology, Cancer }\end{array}$ \\
\hline 39 & $\begin{array}{l}\text { ACVR1, ACVR1B, ACVR2A, } \\
\text { ANTXR1, APC, ASAP2, BCAP31, } \\
\text { BIN1, BMP2, BMP6, BMP7, } \\
\text { BMPR2, BMPR1A, CANX, } \\
\text { COL18A1, CTNNB1, DCTN1, } \\
\text { EFNB2, ERBB2, F10, ICAM1, ID1, } \\
\text { ITGB2, MAPRE1, NOG, NRP1, } \\
\text { PLP2, SEC23A, TGFB1, TLN1, } \\
\text { TNFRSF21 }\end{array}$ & $10 \mathrm{E}-3$ & 16 & $\begin{array}{l}\text { Cell Signaling, Cellular } \\
\text { Development, Connective } \\
\text { Tissue Development and } \\
\text { Function }\end{array}$ \\
\hline
\end{tabular}


TABle 2: Continued.

\begin{tabular}{|c|c|c|c|c|}
\hline ID & Molecules in network & $P$-value & $\begin{array}{c}\text { Focus } \\
\text { molecules }\end{array}$ & Top functions \\
\hline 40 & $\begin{array}{l}\text { ARCN1, BRCA2, BRIP1, COPB1, } \\
\text { COPG, CYLD, EXO1, HERC2, } \\
\text { KPNA2, KPNB1, MAD2L2, } \\
\text { MLH1, MMS19, MSH6, } \\
\text { PIK3C2A, PMS1, PMS2, PSD2, } \\
\text { PSMC1, RANBP9, REV1, REV3L, } \\
\text { RFC2, RUFY1, SACM1L, SBF2, } \\
\text { SSB (includes EG:6741), TMED9, } \\
\text { UBA52, UBR5, USP5 }\end{array}$ & $10 \mathrm{E}-2$ & 15 & $\begin{array}{l}\text { DNA Replication, } \\
\text { Recombination, and Repair, } \\
\text { Cancer, Gastrointestinal } \\
\text { Disease }\end{array}$ \\
\hline 41 & $\begin{array}{l}\text { CCNB1, CD44, EGFR, EIF3A, } \\
\text { ERBB2, ERRFI1, GAB1, IL6ST, } \\
\text { JARID1B, KRT7, MYBL2, MYO10, } \\
\text { NEDD9, PARP1, PIK3CA, } \\
\text { PIK3CD, PIK3R1, PIK3R2, } \\
\text { RAB31, SMAD2, SOLH, SOX4, } \\
\text { TGFB1, TGIF1, TGOLN2 } \\
\text { (includes EG:10618), TNF }\end{array}$ & $10 \mathrm{E}-2$ & 13 & $\begin{array}{l}\text { Cell Cycle, Cellular Growth and } \\
\text { Proliferation, Carbohydrate } \\
\text { Metabolism }\end{array}$ \\
\hline 42 & $\begin{array}{l}\text { ADCYAP1, AMPD3 (includes } \\
\text { EG:272), CCL3, CCL4, CCL5, } \\
\text { CD40, CD40LG, CSF3, CXCL10, } \\
\text { DUSP1, DUSP6, FURIN, IER2, } \\
\text { IL3, IL17A (includes EG:3605), } \\
\text { IL1B, ITGAM, MAP2K6, MAPK3, } \\
\text { MAPK14, MMP9, NAMPT, } \\
\text { NFKB2, NGF, NR4A2, NSMAF, } \\
\text { P2RX7, PLD1, PLG, PTGFR, } \\
\text { SERPINB2, TOB1, TRAF3, } \\
\text { TSC22D3, VEGFA }\end{array}$ & $10 \mathrm{E}-2$ & 16 & $\begin{array}{l}\text { Cellular Movement, } \\
\text { Hematological System } \\
\text { Development and Function, } \\
\text { Immune Cell Trafficking }\end{array}$ \\
\hline 43 & $\begin{array}{l}\text { ATM, ATR (includes EG:545), } \\
\text { C10ORF119, CDC6, CDC37, } \\
\text { CDC25A, CDC25B, CHEK1, } \\
\text { CHEK2, CSNK1A1, E2F1, FAS, } \\
\text { GRB10, MAP3K11, MAP3K5 } \\
\text { (includes EG:4217), MCM2, } \\
\text { MCM3, MCM4, MCM7, MDM4, } \\
\text { PLK1, PPP2R3A (includes } \\
\text { EG:5523), PPP5C, RAD17, RAF1, } \\
\text { SNAP23, SSH2, STX4, STX6, } \\
\text { STX16, TP53, VAMP2, VAMP3, } \\
\text { VIM, YWHAB }\end{array}$ & $10 \mathrm{E}-2$ & 16 & $\begin{array}{l}\text { DNA Replication, } \\
\text { Recombination, and Repair, } \\
\text { Cancer, Cell Cycle }\end{array}$ \\
\hline 44 & $\begin{array}{l}\text { BAK1, BAX, BCL2, BCL2L1, BID, } \\
\text { BMF, BSG, CAV1, CAV3, CDC2, } \\
\text { CDK2, CIT, CYCS (includes } \\
\text { EG:54205), DLG4, ECT2, GIT1, } \\
\text { GRIN2A, HINT1, HTT, IGFBP5, } \\
\text { KIF14, KIF23, KRAS, LRP1, } \\
\text { MEOX2, NCL, NCSTN, NT5C3, } \\
\text { PLK1, PRC1, PSEN1, PSEN2, } \\
\text { RACGAP1, TP53, VDAC2 }\end{array}$ & $10 \mathrm{E}-2$ & 15 & Cell Death, Cell Cycle, Cancer \\
\hline 45 & $\begin{array}{l}\text { ASCL2, ASF1A, ATXN7, CCNH, } \\
\text { CDK7, CRIP2, CSPG4, DKK1, } \\
\text { ENO3, ERCC2, ERCC3, ESRRA, } \\
\text { GK, GPR64, GTF2H1, GTF2H2, } \\
\text { HMGN1, MLL2, MNAT1, NR2C2, } \\
\text { NT5E, PPARGC1A, RBBP5, SAFB, } \\
\text { SMAD6, TAF1, TAF2, TAF4, } \\
\text { TAF8, TAF9, TAF11, TAF15, TFF1, } \\
\text { TUBB, UTX }\end{array}$ & $10 \mathrm{E}-2$ & 15 & $\begin{array}{l}\text { Gene Expression, DNA } \\
\text { Replication, Recombination, } \\
\text { and Repair, Dermatological } \\
\text { Diseases and Conditions }\end{array}$ \\
\hline
\end{tabular}


TABle 2: Continued.

\begin{tabular}{|c|c|c|c|c|}
\hline ID & Molecules in network & $P$-value & $\begin{array}{c}\text { Focus } \\
\text { molecules }\end{array}$ & Top functions \\
\hline 46 & $\begin{array}{l}\text { ADAMTS5, BAX, BCL2, BCL2L1, } \\
\text { BRCA1, CASP3, CCL3, CCL4, } \\
\text { CD226, CD244, CSF2, FLNB, } \\
\text { GP9, GP1BA, IL8, IL15, IL18, } \\
\text { IL18R1, KLRK1, LCP2, MMP1 } \\
\text { (includes EG:4312), MNT, } \\
\text { MOAP1, NCR1, PDIA3, RAB9A, } \\
\text { SELL, SOD2, TERT, TP63, } \\
\text { VDAC1, XRCC6, YWHAE, } \\
\text { YWHAQ (includes EG:10971), } \\
\text { YWHAZ }\end{array}$ & $10 \mathrm{E}-2$ & 15 & $\begin{array}{l}\text { Cell-to-Cell Signaling and } \\
\text { Interaction, Hematological } \\
\text { System Development and } \\
\text { Function, Cell Death }\end{array}$ \\
\hline 47 & $\begin{array}{l}\text { ABCA1, AKT1, APOA1, } \\
\text { CCDC88A, CCL2, CCL5, } \\
\text { COL2A1, CSH1, CUL5, FKBP1A, } \\
\text { FLOT1, IGF1, IL8, IL13, IL1B, } \\
\text { IL1RN, ILK, INS, LOX, MMP7, } \\
\text { PDE4D, PDPK1, PGF, RNF4, } \\
\text { RYR1 (includes EG:6261), } \\
\text { SLC2A4, STK38L (includes } \\
\text { EG:23012), TNF, TRPS1 }\end{array}$ & $10 \mathrm{E}-2$ & 13 & $\begin{array}{l}\text { Cell-mediated Immune } \\
\text { Response, Cellular Movement, } \\
\text { Lipid Metabolism }\end{array}$ \\
\hline 48 & EIF2C1, EIF2C2, TNRC6A & $10 \mathrm{E}-2$ & 3 & $\begin{array}{l}\text { Infection Mechanism, Cancer, } \\
\text { Respiratory Disease }\end{array}$ \\
\hline 49 & DMD, DTNA, DTNB & $10 \mathrm{E}-2$ & 3 & $\begin{array}{l}\text { Cellular Assembly and } \\
\text { Organization, Nervous System } \\
\text { Development and Function, } \\
\text { Skeletal and Muscular System } \\
\text { Development and Function }\end{array}$ \\
\hline
\end{tabular}

selected miRNAs in the ectopic tissue by setting as 1 the expression of eutopic miRNAs. The results obtained by realtime RT-PCR are in accordance with those obtained from the microarray. Indeed, these miRNAs showed significant differential expression $(P$-values $<.05)$ in eutopic versus ectopic tissue: hsa-miR-200a, hsa-miR-200b, hsa-miR-200c, and hsamiR-182 levels in ectopic endometrium were reduced up to 95\% (Figures 1(a)-1(d)), while hsa-miR-202 expression in ectopic endometrium was increased up to 60 folds compared to eutopic endometrium (Figure 1(e)). The analysis of data according to the severity of the endometrioma, by means of nonparametric Wilcoxon and Mann-Whitney $U$ tests, failed to reveal any significant differences in miRNA expression levels, although this may be ascribable to the group size. Further studies increasing the cohort will be necessary to completely address this issue.

\subsection{Identification of Predicted miRNA Targets and In Silico} Functional Analysis. The predicted target mRNAs of the differentially expressed miRNAs common to two different search algorithms, TARGETSCAN (http://www.targetscan .org/) and PICTAR-VERT (http://pictar.mdc-berlin.de), were 3093. The functions of these predicted targets and the molecular pathways in which they could be involved were assessed using Ingenuity Pathways Analysis software (Ingenuity IPA 7.5). The predicted targets were uploaded in IPA, and the software identified 49 significant molecular networks to which the predicted targets of the differentially expressed miRNAs belong (Table 2). Among the biological functions reported to be statistically significant by IPA there were functions known to be involved in endometriosis such as gene expression, cellular growth and proliferation, cellular development, cellular movement, cell death, cell cycle, cancer, and reproductive system disorders. One of the subcategories of reproductive system disorders to be more represented, with $P$-value (calculated by Fisher's Exact test) of $6.1 \cdot 10^{-18}$, was endometriosis with 119 molecules directly involved in this pathology (Table 3).

An exemplificative network identified by IPA enriched for miRNA targets involved in endometriosis is shown in Figure 2. This network, converging on estrogen receptor 1 (ESR1), includes the DNA methyltransferases DNMT3A and DNMT3B that are validated targets of hsa-miR-29b and hsa-miR-29c, and of hsa-miR-29b, hsa-miR-29c, and hsamiR-148a, respectively $[45,46]$. DNA methylation is an epigenetic modification that is involved in gene silencing, chromatin remodeling, and genome stability [47]. It has been demonstrated that DNMT1, DNMT3A, and DNMT3B are disregulated in endometriosis [48], and it has been suggested that aberrant methylation of HOXA10 and of the progesterone receptor PR-B may be responsible of the disregulation of their expression in endometriosis. Thus, this network strongly suggests a possible involvement of miRNAs in these mechanisms. 
TABLE 3: Molecules directly involved in endometriosis and networks in which they appear. IPA analysis indicated that several networks constituted by the predicted targets of the differentially expressed miRNAs include molecules known to be involved in endometriosis.

\begin{tabular}{|c|c|c|c|}
\hline & Symbol & Entrez Gene Name & Networks \\
\hline \multirow{10}{*}{ Cytokines } & CD40LG & CD40 ligand & 38 \\
\hline & CX3CL1 & chemokine (C-X3-C motif) ligand 1 & 12 \\
\hline & CXCL13 & chemokine (C-X-C motif) ligand 13 & 36 \\
\hline & IL2 & interleukin 2 & $2,29,37$ \\
\hline & IL4 & interleukin 4 & $29,32,37$ \\
\hline & IL6 & interleukin 6 (interferon, beta 2) & 29 \\
\hline & IL8 & interleukin 8 & 28,31 \\
\hline & IL18 & $\begin{array}{l}\text { interleukin } 18 \\
\text { (interferon-gamma-inducing factor) }\end{array}$ & 29 \\
\hline & SPP1 & secreted phosphoprotein 1 & 23,46 \\
\hline & TNF & $\begin{array}{l}\text { tumor necrosis factor (TNF } \\
\text { superfamily, member 2) }\end{array}$ & $\begin{array}{l}26,29,30 \\
33,37,38 \\
40,41,45\end{array}$ \\
\hline \multirow{18}{*}{ Enzymes } & CNTN1 & contactin 1 & 23 \\
\hline & DNMT1 & $\begin{array}{l}\text { DNA (cytosine-5-)-methyltransferase } \\
1\end{array}$ & 5,36 \\
\hline & DNMT3A & $\begin{array}{l}\text { DNA (cytosine-5-)-methyltransferase } \\
3 \text { alpha }\end{array}$ & 5 \\
\hline & DNMT3B & $\begin{array}{l}\text { DNA (cytosine-5-)-methyltransferase } \\
3 \text { beta }\end{array}$ & 5 \\
\hline & FN1 & fibronectin 1 & 7,28 \\
\hline & GNAS & GNAS complex locus & 41 \\
\hline & GSTP1 & glutathione S-transferase pi 1 & 49 \\
\hline & HINT1 & $\begin{array}{l}\text { histidine triad nucleotide binding } \\
\text { protein } 1\end{array}$ & 48 \\
\hline & KRAS & $\begin{array}{l}\text { v-Ki-ras2 Kirsten rat sarcoma viral } \\
\text { oncogene homolog }\end{array}$ & 3 \\
\hline & PDE4A & $\begin{array}{l}\text { phosphodiesterase } 4 \mathrm{~A} \text {, cAMP-specific } \\
\text { (phosphodiesterase E2 dunce } \\
\text { homolog, Drosophila) }\end{array}$ & 44 \\
\hline & PDE4D & $\begin{array}{l}\text { phosphodiesterase } 4 \mathrm{D} \text {, cAMP-specific } \\
\text { (phosphodiesterase E3 dunce } \\
\text { homolog, Drosophila) }\end{array}$ & 41 \\
\hline & PTGS2 & $\begin{array}{l}\text { prostaglandin-endoperoxide synthase } \\
2 \text { (prostaglandin G/H synthase and } \\
\text { cyclooxygenase) }\end{array}$ & 7,28 \\
\hline & $\mathrm{RAC1}$ & $\begin{array}{l}\text { ras-related C3 botulinum toxin } \\
\text { substrate } 1 \text { (rho family, small GTP } \\
\text { binding protein Rac1) }\end{array}$ & 5 \\
\hline & RAP1B & $\begin{array}{l}\text { RAP1B, member of RAS oncogene } \\
\text { family }\end{array}$ & 23 \\
\hline & REV3L & $\begin{array}{l}\text { REV3-like, catalytic subunit of DNA } \\
\text { polymerase zeta (yeast) }\end{array}$ & 39 \\
\hline & RRM1 (includes EG:6240) & ribonucleotide reductase M1 & 26 \\
\hline & SAT1 & $\begin{array}{l}\text { spermidine/spermine } \\
\text { N1-acetyltransferase } 1\end{array}$ & 26 \\
\hline & XRCC6 & $\begin{array}{l}\text { X-ray repair complementing defective } \\
\text { repair in Chinese hamster cells } 6\end{array}$ & 42,48 \\
\hline
\end{tabular}


Table 3: Continued.

\begin{tabular}{|c|c|c|c|}
\hline & Symbol & Entrez Gene Name & Networks \\
\hline \multirow{7}{*}{ Growth Factors } & ANGPT2 & angiopoietin 2 & 7 \\
\hline & CTGF & connective tissue growth factor & $2,36,40$ \\
\hline & FGF2 & fibroblast growth factor 2 (basic) & 23,31 \\
\hline & INHBA & inhibin, beta $\mathrm{A}$ & 45 \\
\hline & LEP & leptin & 6 \\
\hline & TGFB1 & transforming growth factor, beta 1 & $\begin{array}{l}20,26,33 \\
35,40,45\end{array}$ \\
\hline & VEGFA & vascular endothelial growth factor A & 29,30 \\
\hline \multirow[t]{2}{*}{ Ion Channels } & PKD1 & $\begin{array}{l}\text { polycystic kidney disease } 1 \text { (autosomal } \\
\text { dominant) }\end{array}$ & 45 \\
\hline & PKD2 (includes EG:5311) & $\begin{array}{l}\text { polycystic kidney disease } 2 \text { (autosomal } \\
\text { dominant) }\end{array}$ & 45 \\
\hline \multirow{17}{*}{ Kinases } & $\mathrm{CDC} 2$ & $\begin{array}{l}\text { cell division cycle } 2, \mathrm{G} 1 \text { to } \mathrm{S} \text { and } \mathrm{G} 2 \text { to } \\
\mathrm{M}\end{array}$ & 32,36 \\
\hline & CSF1R & colony stimulating factor 1 receptor & 3,34 \\
\hline & EGFR & $\begin{array}{l}\text { epidermal growth factor receptor } \\
\text { (erythroblastic leukemia viral } \\
\text { (v-erb-b) oncogene homolog, avian) }\end{array}$ & 28 \\
\hline & ERBB2 & $\begin{array}{l}\text { v-erb-b2 erythroblastic leukemia viral } \\
\text { oncogene homolog } 2 \text {, } \\
\text { neuro/glioblastoma derived oncogene } \\
\text { homolog (avian) }\end{array}$ & $\begin{array}{l}27,30,33 \\
35,38,40 \\
\quad 45,47\end{array}$ \\
\hline & FLT1 & $\begin{array}{l}\text { fms-related tyrosine kinase } 1 \text { (vascular } \\
\text { endothelial growth factor/vascular } \\
\text { permeability factor receptor) }\end{array}$ & 2 \\
\hline & INSR & insulin receptor & 26 \\
\hline & JAK1 & $\begin{array}{l}\text { Janus kinase } 1 \text { (a protein tyrosine } \\
\text { kinase) }\end{array}$ & 37 \\
\hline & KIT & $\begin{array}{l}\text { v-kit Hardy-Zuckerman } 4 \text { feline } \\
\text { sarcoma viral oncogene homolog }\end{array}$ & 9 \\
\hline & MAPK4 & mitogen-activated protein kinase 4 & 17 \\
\hline & NTRK2 & $\begin{array}{l}\text { neurotrophic tyrosine kinase, receptor, } \\
\text { type } 2\end{array}$ & 45 \\
\hline & PCK1 & $\begin{array}{l}\text { phosphoenolpyruvate carboxykinase } 1 \\
\text { (soluble) }\end{array}$ & 42 \\
\hline & PDGFRA & $\begin{array}{l}\text { platelet-derived growth factor } \\
\text { receptor, alpha polypeptide }\end{array}$ & 11 \\
\hline & PDGFRB & $\begin{array}{l}\text { platelet-derived growth factor } \\
\text { receptor, beta polypeptide }\end{array}$ & 11 \\
\hline & PIK3R2 & $\begin{array}{l}\text { phosphoinositide-3-kinase, regulatory } \\
\text { subunit } 2 \text { (beta) }\end{array}$ & 17 \\
\hline & SGK1 & $\begin{array}{l}\text { serum/glucocorticoid regulated kinase } \\
1\end{array}$ & 16 \\
\hline & STC1 & stanniocalcin 1 & 49 \\
\hline & WEE1 & WEE1 homolog (S. pombe) & 18 \\
\hline \multirow{4}{*}{$\begin{array}{l}\text { Ligand-Dependent } \\
\text { Nuclear Receptors }\end{array}$} & AHR & aryl hydrocarbon receptor & 44 \\
\hline & AR & androgen receptor & 30 \\
\hline & ESR1 & estrogen receptor 1 & $5,30,44$ \\
\hline & ESR2 & estrogen receptor 2 (ER beta) & 44 \\
\hline
\end{tabular}


TABle 3: Continued.

\begin{tabular}{|c|c|c|c|}
\hline & Symbol & Entrez Gene Name & Networks \\
\hline & PPARG & $\begin{array}{l}\text { peroxisome proliferator-activated } \\
\text { receptor gamma }\end{array}$ & 12,29 \\
\hline \multirow{3}{*}{ Peptidases } & HPR (includes EG:3250) & haptoglobin-related protein & 24 \\
\hline & MEST & $\begin{array}{l}\text { mesoderm specific transcript homolog } \\
\text { (mouse) }\end{array}$ & 18 \\
\hline & MMP2 & $\begin{array}{l}\text { matrix metallopeptidase } 2 \text { (gelatinase } \\
\text { A, } 72 \mathrm{kDa} \text { gelatinase, } 72 \mathrm{kDa} \text { type IV } \\
\text { collagenase) }\end{array}$ & 11 \\
\hline \multirow{4}{*}{ Phosphatases } & DUSP1 & dual specificity phosphatase 1 & 3 \\
\hline & PPP3R1 & $\begin{array}{l}\text { protein phosphatase } 3 \text { (formerly } 2 \mathrm{~B} \text { ), } \\
\text { regulatory subunit } \mathrm{B} \text {, alpha isoform }\end{array}$ & 24 \\
\hline & PTEN & phosphatase and tensin homolog & 19 \\
\hline & PTP4A1 & $\begin{array}{l}\text { protein tyrosine phosphatase type IVA, } \\
\text { member } 1\end{array}$ & 22 \\
\hline \multirow{21}{*}{$\begin{array}{l}\text { Transcription } \\
\text { Regulators }\end{array}$} & BCL6 & B-cell CLL/lymphoma 6 & 16 \\
\hline & BRCA1 & breast cancer 1 , early onset & $5,30,42$ \\
\hline & CITED2 & $\begin{array}{l}\mathrm{Cbp} / \mathrm{p} 300 \text {-interacting transactivator, } \\
\text { with Glu/Asp-rich carboxy-terminal } \\
\text { domain, } 2\end{array}$ & 11 \\
\hline & CREB1 & $\begin{array}{l}\text { cAMP responsive element binding } \\
\text { protein } 1\end{array}$ & 6 \\
\hline & EGR1 & early growth response 1 & $6,26,35$ \\
\hline & EMX2 & empty spiracles homeobox 2 & 15 \\
\hline & FOS & $\begin{array}{l}\text { v-fos FBJ murine osteosarcoma viral } \\
\text { oncogene homolog }\end{array}$ & $6,35,49$ \\
\hline & FOXO1 & forkhead box O1 & 3 \\
\hline & GATA3 & GATA binding protein 3 & 2 \\
\hline & HIF1A & $\begin{array}{l}\text { hypoxia inducible factor } 1 \text {, alpha } \\
\text { subunit (basic helix-loop-helix } \\
\text { transcription factor) }\end{array}$ & $\begin{array}{l}10,31,44 \\
\quad 47\end{array}$ \\
\hline & ID1 & $\begin{array}{l}\text { inhibitor of DNA binding 1, dominant } \\
\text { negative helix-loop-helix protein }\end{array}$ & 47,50 \\
\hline & JUN & jun oncogene & 49 \\
\hline & JUNB & jun B proto-oncogene & 11,47 \\
\hline & NRIP1 & nuclear receptor interacting protein 1 & 36 \\
\hline & REL & $\begin{array}{l}\text { v-rel reticuloendotheliosis viral } \\
\text { oncogene homolog (avian) }\end{array}$ & 44 \\
\hline & SMAD6 & SMAD family member 6 & 14 \\
\hline & SMAD7 & SMAD family member 7 & 11 \\
\hline & SP2 & Sp2 transcription factor & 31 \\
\hline & TP53 & tumor protein p53 & $\begin{array}{l}22,27,32 \\
34,36,37 \\
40,41,45\end{array}$ \\
\hline & WT1 & Wilms tumor 1 & 7 \\
\hline & ZFP36 & $\begin{array}{l}\text { zinc finger protein } 36, \mathrm{C} 3 \mathrm{H} \text { type, } \\
\text { homolog (mouse) }\end{array}$ & 20 \\
\hline \multirow{3}{*}{$\begin{array}{l}\text { Transmembrane } \\
\text { Receptors }\end{array}$} & IL2RG & $\begin{array}{l}\text { interleukin } 2 \text { receptor, gamma (severe } \\
\text { combined immunodeficiency) }\end{array}$ & 37 \\
\hline & ITGB1 & $\begin{array}{l}\text { integrin, beta } 1 \text { (fibronectin receptor, } \\
\text { beta polypeptide, antigen CD29 } \\
\text { includes MDF2, MSK12) }\end{array}$ & $11,28,30$ \\
\hline & ITGB3 & $\begin{array}{l}\text { integrin, beta } 3 \text { (platelet glycoprotein } \\
\text { IIIa, antigen CD61) }\end{array}$ & 7 \\
\hline
\end{tabular}


Table 3: Continued.

\begin{tabular}{|c|c|c|c|}
\hline & Symbol & Entrez Gene Name & Networks \\
\hline & ITGB4 & integrin, beta 4 & 30 \\
\hline \multirow{4}{*}{ Transporters } & APOE & apolipoprotein E & 36 \\
\hline & ATP1B1 & $\begin{array}{l}\text { ATPase, } \mathrm{Na}^{+} / \mathrm{K}^{+} \text {transporting, beta } 1 \\
\text { polypeptide }\end{array}$ & 41 \\
\hline & ATP2B2 & $\begin{array}{l}\text { ATPase, } \mathrm{Ca}^{++} \text {transporting, plasma } \\
\text { membrane } 2\end{array}$ & 21 \\
\hline & SLC6A6 & $\begin{array}{l}\text { solute carrier family } 6 \\
\text { (neurotransmitter transporter, } \\
\text { taurine), member } 6\end{array}$ & 1 \\
\hline \multirow{24}{*}{ Others } & ACTB & actin, beta & 9,49 \\
\hline & ANK3 & $\begin{array}{l}\text { ankyrin 3, node of Ranvier (ankyrin } \\
\text { G) }\end{array}$ & 24 \\
\hline & BCL2 & B-cell CLL/lymphoma 2 & 3,48 \\
\hline & BIRC5 & baculoviral IAP repeat-containing 5 & 36 \\
\hline & BSG & basigin (Ok blood group) & 41 \\
\hline & CAV2 & caveolin 2 & 5 \\
\hline & CCNA2 & cyclin A2 & 43 \\
\hline & COL18A1 & collagen, type XVIII, alpha 1 & 47 \\
\hline & DCN & decorin & 28 \\
\hline & EPS15 & $\begin{array}{l}\text { epidermal growth factor receptor } \\
\text { pathway substrate } 15\end{array}$ & 28 \\
\hline & ERRFI1 & ERBB receptor feedback inhibitor 1 & 45 \\
\hline & EZR & ezrin & 18 \\
\hline & FBN1 & fibrillin 1 & 36 \\
\hline & IRS2 & insulin receptor substrate 2 & 6,37 \\
\hline & ITGA6 & integrin, alpha 6 & 30 \\
\hline & LRP5 & $\begin{array}{l}\text { low density lipoprotein } \\
\text { receptor-related protein } 5\end{array}$ & 6 \\
\hline & $\begin{array}{l}\text { MARCKS (includes } \\
\text { EG:4082) }\end{array}$ & $\begin{array}{l}\text { myristoylated alanine-rich protein } \\
\text { kinase C substrate }\end{array}$ & 47 \\
\hline & SDC2 & syndecan 2 & 8 \\
\hline & TAL1 & T-cell acute lymphocytic leukemia 1 & 18 \\
\hline & THBS2 & thrombospondin 2 & 11 \\
\hline & TIMP2 & TIMP metallopeptidase inhibitor 2 & 11 \\
\hline & TMSB10 & thymosin beta 10 & 19 \\
\hline & TRAF2 & TNF receptor-associated factor 2 & 26 \\
\hline & VIM & vimentin & 19,36 \\
\hline
\end{tabular}

To further analyze the possible role of these differentially expressed miRNAs in endometriosis, we performed a different analysis uploading the miRNAs directly in IPA. In this way, the software identified 6 networks, 3 of which are highly significant with known biological functions including genetic disorders, connective tissue disorders, skeletal and muscular disorders, cancer, and reproductive system disorders (Table 4).

The difference in the number of networks identified by IPA is ascribable to the different database used by the software, as IPA uses the Argonaute 2 databases (http://www.ma.uni-heidelberg.de/apps/zmf/argonaute/) to analyse miRNAs and their known or predicted targets, and this database identified only 118 targets for the 50 miRNAs.
Next, we performed an IPA analysis on the 1203 predicted targets of the miRNAs whose differential expression between eutopic and ectopic tissue was confirmed by realtime RT-PCR. IPA software identified 49 networks and revealed that the predicted targets were enriched for biological functions such as cellular development, cell morphology, cell-mediated immune response, gene expression, cell cycle, cell death, cancer, and developmental disorders. The network with the highest score from this analysis, shown in Figure 3, includes molecules that have been implicated in endometriosis such as the TNF receptor, IL10, IL6, and FOXO1 [49-55].

Performing the analysis uploading directly the miRNAs in IPA, thus using the Argonaute2 database, the software identified only one network (Figure 4), the major biological 
TABLE 4: Molecular networks constituted by the predicted miRNA targets. The list of differentially expressed miRNAs was directly uploaded in IPA and an analysis was performed in order to identify the molecular pathways and functions to which the predicted targets of the differentially expressed miRNAs belong. The database used by IPA to analyze miRNAs and their targets is Argonaute2 (http://www.ma.uni-heidelberg.de/apps/zmf/argonaute/). $P<.01$.

\begin{tabular}{|c|c|c|c|c|}
\hline ID & Molecules in Network & $P$-value & $\begin{array}{c}\text { Focus } \\
\text { Molecules }\end{array}$ & Top Functions \\
\hline 1 & $\begin{array}{l}\text { AKAP3, ATP2A2, C11ORF87, CNKSR2, } \\
\text { CREB1, CUGBP2, EIF4E3, ELK1, FLRT2, } \\
\text { HOXB2, HOXD12, IFNG, KLHDC10, } \\
\text { KPNB1, MIR25, MIR150, MIR186, } \\
\text { MIR221, MIR299, MIR143 (includes } \\
\text { EG:406935), MIR182 (includes } \\
\text { EG:406958), MIR200A, MIR200B, } \\
\text { MIR200C, MIR34A, MYST4, OTOF, } \\
\text { PAQR3, PER1, RPGRIP1L, SNRPA, } \\
\text { SRCAP, UBFD1, USP6NL, WDR44 }\end{array}$ & $10 \mathrm{E}-24$ & 11 & $\begin{array}{l}\text { Genetic Disorder, Skeletal and } \\
\text { Muscular Disorders, } \\
\text { Connective Tissue Disorders }\end{array}$ \\
\hline 2 & $\begin{array}{l}\text { ATP1B1, C4ORF16, CALU, DHX15, } \\
\text { DIP2C, DNMT3A, DNMT3B, EVX2, } \\
\text { FAM108C1, FBXL11, HOXA5, HOXA10, } \\
\text { INO80, JPH3, KLHL18, MACF1, } \\
\text { MAP2K6, MIR126, MIR100 (includes } \\
\text { EG:406892), MIR130A (includes } \\
\text { EG:406919), MIR130B (includes } \\
\text { EG:406920), MIR132 (includes } \\
\text { EG:406921), MIR148A (includes } \\
\text { EG:406940), MIR20A, MIR29B, } \\
\text { MIR29B1, MIR29B2, MIR29C, MPPED2 } \\
\text { (includes EG:744), NUFIP2, SMARCE1, } \\
\text { SOX6, ZFP36L2, ZNF238, ZNF318 } \\
\text { (includes EG:24149) }\end{array}$ & $10 \mathrm{E}-19$ & 9 & $\begin{array}{l}\text { Genetic Disorder, Skeletal and } \\
\text { Muscular Disorders, Infection } \\
\text { Mechanism }\end{array}$ \\
\hline 3 & $\begin{array}{l}\text { ADIPOR2, AR, ARF4, CAND1, CCNT2, } \\
\text { CDKN1A, CHSY1, FBXW7, FNDC3B, } \\
\text { IRS1, JUN, KLF6, LASS2, MAP1D, } \\
\text { MDM2, MIR93, MIR375, MIR1 } \\
\text { (human), MIR106A (includes } \\
\text { EG:406899), MIR106B (includes } \\
\text { EG:406900), MIR145 (includes } \\
\text { EG:406937), MIR183 (includes } \\
\text { EG:406959), MIR196B, MIR99A, MTPN, } \\
\text { NPAT, NPPC, PDCD4, PFTK1, PPM1D, } \\
\text { SERP1, SERPINB5, SLC16A2, TDG, } \\
\text { TRIM2 }\end{array}$ & $10 \mathrm{E}-18$ & 9 & $\begin{array}{l}\text { Cancer, Reproductive System } \\
\text { Disease, Cell Cycle }\end{array}$ \\
\hline 4 & MIR376A, MIR376A1, MIR376A2 & $10 \mathrm{E}-2$ & 1 & $\begin{array}{l}\text { Genetic Disorder, Skeletal and } \\
\text { Muscular Disorders }\end{array}$ \\
\hline 5 & MIR365, MIR365-1, MIR365-2 & $10 \mathrm{E}-2$ & 1 & \\
\hline 6 & $\begin{array}{l}\text { EZH2, MIR101, MIR101-1, MIR101-2, } \\
\text { MYCN }\end{array}$ & $10 \mathrm{E}-2$ & 1 & $\begin{array}{l}\text { Cancer, Cellular Movement, } \\
\text { Reproductive System Disease }\end{array}$ \\
\hline
\end{tabular}

functions of which are cell cycle, cell death, and connective tissue disorders. This network contains PIK3R1, and its expression has been demonstrated to be upregulated in endometriosis, were it can play an essential role in TNFmediated antiapoptotic signaling [56]. Another interesting molecule present in this pathway is SIP1, a validated target of the miR-200 family, which is a factor implicated in epithelial to mesenchymal transition and tumor metastasis [57]. Thus, the observed downregulation of miR-200 family in the ectopic endometrium may have a role in the endometrial lesion development.
We further investigated the function of the predicted targets of the RT-PCR-validated miRNAs by using OntoExpress and Pathway-Express (http://vortex.cs.wayne.edu/) in order to categorize the targets according to Gene Ontology (GO) and KEGG pathways, respectively [58, 59]. The predicted targets of the validated miRNAs were uploaded in Onto-Express and the list of the putative targets of the 475 miRNAs assayed was used as reference. OntoExpress calculates the mRNA targets in each GO category and compares it with the expected number of targets present in the GO category. Significant differences from 
TABle 5: Gene Ontology analysis of the predicted target genes of 50 miRNAs differentially expressed. Onto-Express analysis on predicted targets of the differentially expressed miRNAs identified enrichment for biological process categories. The gene column indicates the number of predicted targets of the differentially expressed miRNAs upon the number of the targets of all miRNAs considered for the study. Significant differences from the number of targets in each GO category with the expected number of genes were calculated with the assumption of a hypergeometric distribution and $P$-values were adjusted with the false discovery rate (fdr) correction. $P<.05$.

\begin{tabular}{|c|c|c|c|}
\hline Rank & Biological process category & Genes & $\begin{array}{c}\text { Corrected } \\
P \text {-value }\end{array}$ \\
\hline \multirow[t]{26}{*}{1} & Cellular process & $2408 / 6644$ & .0 \\
\hline & Cell motion & $148 / 330$ & .0 \\
\hline & Cell communication & $908 / 2223$ & .0 \\
\hline & Cellular component organization & $546 / 1383$ & .0 \\
\hline & Cellular developmental process & $400 / 949$ & .0 \\
\hline & Cellular metabolic process & $1563 / 4269$ & .0 \\
\hline & Regulation of cellular process & $1555 / 3840$ & .0 \\
\hline & Cell development & $183 / 419$ & .0 \\
\hline & Positive regulation of cellular process & $371 / 875$ & .0 \\
\hline & Negative regulation of cellular process & $394 / 932$ & .0 \\
\hline & Cell cycle & $223 / 555$ & $1.0 \mathrm{E}-5$ \\
\hline & Cell death & $235 / 587$ & $2.0 \mathrm{E}-5$ \\
\hline & Cell proliferation & $237 / 602$ & $5.0 \mathrm{E}-5$ \\
\hline & Actin-filament based process & $90 / 197$ & $6.0 \mathrm{E}-5$ \\
\hline & Cell fate commitment & $45 / 83$ & $9.0 \mathrm{E}-5$ \\
\hline & Cell aging & $14 / 21$ & $7.0 \mathrm{E}-4$ \\
\hline & Vescicle-mediated transport & $158 / 397$ & $7.3 \mathrm{E}-4$ \\
\hline & Cell growth & $51 / 112$ & .00286 \\
\hline & Cell fate determination & $15 / 23$ & .00286 \\
\hline & Cellular localization & $224 / 609$ & .00506 \\
\hline & Gene silencing & $16 / 27$ & .00696 \\
\hline & Cell cycle process & $124 / 323$ & .00696 \\
\hline & Translational initiation & $23 / 48$ & .01253 \\
\hline & Cell fate specification & $12 / 20$ & .01728 \\
\hline & Cellular response to stimulus & $110 / 292$ & .03290 \\
\hline & Cell adhesion & $173 / 479$ & .04094 \\
\hline \multirow[t]{6}{*}{2} & Negative regulation of biological process & $421 / 992$ & .0 \\
\hline & Negative regulation of metabolic process & $193 / 422$ & .0 \\
\hline & Negative regulation to cellular process & $394 / 932$ & .0 \\
\hline & Negative regulation of developmental process & $129 / 309$ & $1.9 \mathrm{E}-4$ \\
\hline & Negative regulation of response to stimulus & $16 / 29$ & .01705 \\
\hline & Negative regulation of growth & $24 / 53$ & .03564 \\
\hline \multirow[t]{5}{*}{3} & Multicellular organismal process & $820 / 2037$ & .0 \\
\hline & Multicellular organismal development & $675 / 1606$ & .0 \\
\hline & Regulation of multicellular organismal process & $171 / 421$ & $2.0 \mathrm{E}-4$ \\
\hline & System process & $227 / 606$ & .00750 \\
\hline & Respiratory gaseous exchange & $11 / 17$ & .01639 \\
\hline \multirow[t]{4}{*}{4} & Biological regulation & $1656 / 4148$ & .0 \\
\hline & Regulation of molecular function & $211 / 478$ & .0 \\
\hline & Regulation of biological process & $1597 / 3961$ & .0 \\
\hline & Regulation of biological quality & $281 / 732$ & $1.3 \mathrm{E}-4$ \\
\hline
\end{tabular}


TABle 5: Continued.

\begin{tabular}{|c|c|c|c|}
\hline Rank & Biological process category & Genes & $\begin{array}{c}\text { Corrected } \\
P \text {-value }\end{array}$ \\
\hline \multirow[t]{10}{*}{5} & Regulation of biological process & $1597 / 3961$ & .0 \\
\hline & Regulation of metabolic process & $850 / 2038$ & .0 \\
\hline & Regulation of developmental process & $283 / 657$ & .0 \\
\hline & Regulation of cellular process & $1555 / 3840$ & .0 \\
\hline & Positive regulation of cellular process & $384 / 933$ & .0 \\
\hline & Negative regulation of cellular process & $421 / 992$ & .0 \\
\hline & Regulation of multicellular organismal process & $171 / 421$ & $1.4 \mathrm{E}-4$ \\
\hline & Regulation of localization & $110 / 261$ & $8.7 \mathrm{E}-4$ \\
\hline & Regulation of locomotion & $41 / 95$ & .02619 \\
\hline & Regulation of growth & $64 / 164$ & .04199 \\
\hline \multirow[t]{11}{*}{6} & Metabolic process & $1631 / 4509$ & .0 \\
\hline & Biosynthetic process & $899 / 2354$ & .0 \\
\hline & Negative regulation of metabolic process & $193 / 422$ & .0 \\
\hline & Positive regulation of metabolic process & $201 / 473$ & .0 \\
\hline & Regulation of metabolic process & $1563 / 2038$ & .0 \\
\hline & Cellular metabolic process & $1563 / 4269$ & .0 \\
\hline & Primary metabolic process & $1551 / 4187$ & .0 \\
\hline & Macromolecule metabolic process & $1383 / 3644$ & .0 \\
\hline & Oxydation reduction & $52 / 255$ & $5.0 \mathrm{E}-5$ \\
\hline & Catabolic process & $237 / 665$ & .01317 \\
\hline & Nitrogen compound metabolic process & $49 / 193$ & .03270 \\
\hline \multirow[t]{14}{*}{7} & Developmental process & $821 / 1967$ & .0 \\
\hline & Multicellular organismal development & $675 / 1606$ & .0 \\
\hline & Anatomical structure morphogenesis & $310 / 710$ & .0 \\
\hline & Embryonic development & $140 / 304$ & .0 \\
\hline & Anatomical structure development & $584 / 1379$ & .0 \\
\hline & Cellular developmental process & $400 / 949$ & .0 \\
\hline & Regulation of developmental process & $283 / 657$ & .0 \\
\hline & Positive regulation of developmental process & $131 / 295$ & $1.0 \mathrm{E}-5$ \\
\hline & Anatomical structure formation involved in Morphogenesis & $97 / 216$ & $4.0 \mathrm{E}-5$ \\
\hline & Pattern specification process & $79 / 173$ & $1.6 \mathrm{E}-4$ \\
\hline & Negative regulation of developmental process & $129 / 309$ & $1.6 \mathrm{E}-4$ \\
\hline & Pigmentation during development & $9 / 13$ & .01264 \\
\hline & Reproductive developmental process & $31 / 68$ & .02708 \\
\hline & Aging & $17 / 36$ & .04082 \\
\hline \multirow[t]{5}{*}{8} & Positive regulation of biological process & $384 / 933$ & .0 \\
\hline & Positive regulation of metabolic process & $201 / 473$ & .0 \\
\hline & Positive regulation of cellular process & $371 / 875$ & .0 \\
\hline & Positive regulation of developmental process & $131 / 295$ & $1.0 \mathrm{E}-5$ \\
\hline & Positive regulation of homeostatic process & $6 / 8$ & .03203 \\
\hline \multirow[t]{6}{*}{9} & Localization & $715 / 1953$ & .0 \\
\hline & Localization of cell & $148 / 330$ & .0 \\
\hline & Macromolecule localization & $247 / 638$ & $1.1 \mathrm{E}-4$ \\
\hline & Regulation of localization & $110 / 261$ & $7.7 \mathrm{E}-4$ \\
\hline & Cellular localization & $224 / 609$ & .00422 \\
\hline & Establishment of localization & $577 / 1657$ & .00463 \\
\hline
\end{tabular}


Table 5: Continued.

\begin{tabular}{|c|c|c|c|c|}
\hline Rank & Biological process category & & Genes & $\begin{array}{c}\text { Corrected } \\
P \text {-value }\end{array}$ \\
\hline \multirow[t]{2}{*}{10} & Death & & $235 / 591$ & $2.0 \mathrm{E}-5$ \\
\hline & Cell death & & $235 / 587$ & $1.0 \mathrm{E}-5$ \\
\hline \multirow[t]{3}{*}{11} & Anatomical structure formation & & $242 / 629$ & $1.1 \mathrm{E}-4$ \\
\hline & Anatomical structure formation involved in & Morphogenesis & $97 / 216$ & $3.0 \mathrm{E}-5$ \\
\hline & Cellular component assembly & & $165 / 452$ & .01276 \\
\hline \multirow[t]{7}{*}{12} & Response to stimulus & & $464 / 1276$ & $2.4 \mathrm{E}-4$ \\
\hline & Response to chemical stimulus & & $185 / 465$ & $5.3 \mathrm{E}-4$ \\
\hline & Response to endogenous stimulus & & $59 / 136$ & .00633 \\
\hline & Negative regulation to response to stimulus & & $16 / 29$ & .01844 \\
\hline & Behavior & & $84 / 215$ & .02638 \\
\hline & Cellular response to stimulus & & $110 / 292$ & .03534 \\
\hline & Response to stress & & $253 / 718$ & .03918 \\
\hline \multirow[t]{3}{*}{13} & Multi-organism process & & $113 / 286$ & .00251 \\
\hline & Interspecies interaction between organisms & & $71 / 172$ & .00565 \\
\hline & Female pregnancy & & $19 / 39$ & .04504 \\
\hline \multirow[t]{4}{*}{14} & Growth & & $96 / 235$ & .00334 \\
\hline & Cell growth & & $51 / 112$ & .00298 \\
\hline & Negative regulation of growth & & $24 / 53$ & .03391 \\
\hline & Regulation of growth & & $64 / 164$ & .03916 \\
\hline \multirow[t]{3}{*}{15} & Locomotion & & $111 / 277$ & .00422 \\
\hline & Cell motility & & $97 / 223$ & $3.5 \mathrm{E}-4$ \\
\hline & Regulation of locomotion & & $41 / 95$ & .02439 \\
\hline \multirow[t]{3}{*}{16} & Establishment of localization & & $577 / 1657$ & .00458 \\
\hline & Establishment of protein localization & & $207 / 536$ & $3.3 \mathrm{E}-4$ \\
\hline & Establishment of localization in cell & & $209 / 576$ & .01045 \\
\hline \multirow[t]{2}{*}{17} & Reproduction & & $117 / 303$ & .00983 \\
\hline & Reproductive process & & $116 / 301$ & .01127 \\
\hline \multirow[t]{3}{*}{18} & Reproductive process & & $116 / 301$ & .01024 \\
\hline & Reproductive developmental process & & $31 / 68$ & .03090 \\
\hline & Female pregnancy & & $19 / 39$ & .04504 \\
\hline \multirow[t]{2}{*}{19} & Biological adhesion & & $173 / 479$ & .03486 \\
\hline & Cell adhesion & & $173 / 479$ & .03486 \\
\hline 20 & Rhythmic process & & $26 / 59$ & .04158 \\
\hline
\end{tabular}

the expected number of genes were calculated assuming a hypergeometric distribution, and $P$ values were adjusted with the false discovery rate correction based on the number of GO categories tested. A corrected $P$ value < .05 was considered statistically significant. Onto-Express analysis revealed enrichment for several biological processes known to be relevant in endometriosis, such as developmental process, cell death, cell cycle, and cell adhesion (Table 5).

Pathway-Express analysis identified 33 pathways significant at 5\% level (Table 6), most of which are coherent with the current knowledge on endometriosis. For instance, the most significant pathways putatively affected by the differential expression of miRNAs are $M A P K$ and axon guidance the latter shown in Figure 5. While MAPK pathway, which is involved in several cellular functions, such as cell proliferation, migration, and differentiation, is clearly relevant for endometriosis, axon guidance, at first may appear unrelated to this pathology. However, nerves and blood vessels are highly interconnected, both physically and in their morphogenesis. Indeed, it has been demonstrated that several molecules involved in axon guidance, such as semaphorins, plexins, and neuropilins, are also strongly implicated in angiogenesis [60], a biological process essential for endometriosis. Intriguingly, this pathway contains ROBO1, and its expression, higher in ectopic endometrium compared to eutopic tissue, positively correlates with endometriosis recurrence [61], thus suggesting that miRNAs may take part in tuning ROBO1 expression and have a role in the recurrence of the pathology. 
TABLE 6: KEGG pathways containing the predicted targets of the differentially expressed miRNAs. Pathway-Express analysis identified the KEGG molecular pathways affected by the predicted targets of the differentially expressed miRNAs. $P<.05$.

\begin{tabular}{|c|c|c|c|c|c|}
\hline Rank & Pathway name & Genes in pathway & Input genes in pathway & Pathway genes on chip & $P$-value \\
\hline 1 & MAPK signaling pathway & 272 & 103 & 197 & $3.23 \mathrm{E}-08$ \\
\hline 2 & Axon guidance & 129 & 67 & 113 & $3.23 \mathrm{E}-08$ \\
\hline 3 & Melanogenesis & 102 & 48 & 74 & $8.60 \mathrm{E}-08$ \\
\hline 4 & Pathways in cancer & 330 & 119 & 245 & $2.27 \mathrm{E}-07$ \\
\hline 5 & Regulation of actin cytoskeleton & 217 & 78 & 158 & $2.31 \mathrm{E}-05$ \\
\hline 6 & Focal adhesion & 203 & 75 & 150 & $2.31 \mathrm{E}-05$ \\
\hline 7 & Wnt signaling pathway & 152 & 63 & 127 & $1.60 \mathrm{E}-04$ \\
\hline 8 & Glioma & 65 & 30 & 50 & $2.94 \mathrm{E}-04$ \\
\hline 9 & GnRH signaling pathway & 103 & 36 & 65 & $4.86 \mathrm{E}-04$ \\
\hline 10 & Renal cell carcinoma & 69 & 34 & 61 & $5.92 \mathrm{E}-04$ \\
\hline 11 & Insulin signaling pathway & 138 & 49 & 98 & $7.02 \mathrm{E}-04$ \\
\hline 12 & Adherens junction & 78 & 34 & 62 & $7.65 \mathrm{E}-04$ \\
\hline 13 & TGF-beta signaling pathway & 87 & 38 & 72 & $8.49 \mathrm{E}-04$ \\
\hline 14 & Prostate cancer & 90 & 36 & 68 & .0011 \\
\hline 15 & ECM-receptor interaction & 84 & 30 & 55 & .0016 \\
\hline 16 & Phosphatidylinositol signaling system & 76 & 30 & 55 & .0016 \\
\hline 17 & Calcium signaling pathway & 182 & 54 & 115 & .0016 \\
\hline 18 & Colorectal cancer & 84 & 36 & 70 & .0018 \\
\hline 19 & Long-term potentiation & 73 & 31 & 58 & .0018 \\
\hline 20 & Adipocytokine signaling pathway & 67 & 27 & 50 & .0032 \\
\hline 21 & ErbB signaling pathway & 87 & 34 & 69 & .0056 \\
\hline 22 & Pancreatic cancer & 72 & 30 & 59 & .0056 \\
\hline 23 & Gap junction & 96 & 33 & 67 & .0063 \\
\hline 24 & Type II diabetes mellitus & 45 & 18 & 31 & .0069 \\
\hline 25 & Small cell lung cancer & 86 & 30 & 61 & .0095 \\
\hline 26 & Thyroid cancer & 29 & 14 & 23 & .0111 \\
\hline 27 & Ubiquitin mediated proteolysis & 138 & 42 & 94 & .0145 \\
\hline 28 & Long-term depression & 75 & 24 & 49 & .0225 \\
\hline 29 & Non-small cell lung cancer & 54 & 20 & 39 & .0225 \\
\hline 30 & Acute myeloid leukemia & 59 & 22 & 45 & .0304 \\
\hline 31 & Melanoma & 71 & 25 & 53 & .0323 \\
\hline 32 & Cardiac muscle contraction & 87 & 20 & 41 & .0402 \\
\hline 33 & Chronic myeloid leukemia & 75 & 28 & 62 & .0410 \\
\hline
\end{tabular}

3.4. Genes Differentially Expressed in Endometriosis Are Predicted Targets of the Differentially Expressed miRNAs. Finally, after the identification of the predicted targets of the differentially expressed miRNAs, we investigated whether they were in accordance with the results of two studies of gene expression in endometriosis. We first analysed the genes reported to be differentially expressed in a study on paired eutopic and ectopic samples of ovarian endometriosis [23]. This study identified 701 differentially expressed transcripts (expression $\geq 0.2$; fold change $\pm \geq 2 ; P \leq .05$ ), 82 of which are predicted target genes of the 50 miRNAs, 51/492 upregulated and 31/209 downregulated. A second study on peritoneal endometriosis [24] identified 622 differentially expressed transcripts (fold change $\pm \geq 1.5 ; P \leq .05$ ), 107 of which are predicted targets of the differentially expressed miRNAs, 73/232 upregulated and 34/390 downregulated.
Hypothesising that the genes differentially expressed common to both studies are likely those specific to endometriosis independently from the site of the lesion, we restricted the analysis to the differentially regulated genes in eutopic and ectopic endometrium common to the two studies that are also predicted targets of the 50 miRNAs (Table 7). IPA analysis identified 5 molecular networks, the most relevant functions of which being cancer, cell cycle, and reproductive system disease (Table 8). The overlap of networks generated by IPA is shown in Figure 6. In this graphical representation the most relevant nodes are the transcription factor SP1, tumor necrosis factor (TNF), and SRC, in remarkable agreement with the nodes of the most significant networks obtained by IPA analysis performed on the distinct datasets of differentially expressed genes in ovarian and peritoneal endometriosis (data not shown). 
TABLE 7: Genes aberrantly expressed in ovarian and peritoneal endometriosis that are predicted targets of the differentially expressed miRNAs. The miRNAs predicted to regulate the expression of the genes known to be aberrantly up- $(\uparrow)$ or downregulated $(\downarrow)$ in both ovarian and peritoneal endometriosis were identified by TARGETSCAN and PICTAR algorithms. MicroRNAs whose regulation is in accordance with the resulting expression of their predicted target genes are reported in bold.

\begin{tabular}{|c|c|c|}
\hline Target genes & microRNAs upregulated & microRNAs downregulated \\
\hline CA3 (carbonic anhydrase III) $\uparrow$ & hsa-miR-29b; hsa-miR-29c & \\
\hline CAV1 (caveolin 1) $\uparrow$ & hsa-miR-199a; hsa-miR-30e-3p & hsa-miR-20a; hsa-miR-106b \\
\hline CAV2 (caveolin 2) $\uparrow$ & hsa-miR-29b; hsa-miR-29c & \\
\hline DMD (dystrophin) $\uparrow$ & hsa-miR-101; hsa-miR-30e-5p & hsa-miR-200b; hsa-miR-200c \\
\hline EPHA3 (EPH receptor A3) $\uparrow$ & hsa-miR-29b; hsa-miR-29c & hsa-miR-182 \\
\hline FZD7 $\uparrow($ frizzled homolog 7 ) & hsa-miR-145; hsa-miR-1 & hsa-miR-20a; hsa-miR-106b \\
\hline $\begin{array}{l}\text { GALNT3 } \\
\text { (UDP-N-acetyl-alpha-D-galactosamine) } \downarrow\end{array}$ & hsa-miR-30e-5p & \\
\hline $\begin{array}{l}\text { KCNMA1 (potassium large conductance } \\
\text { calcium-activated channel, subfamily M, } \\
\text { alpha mamber } 1 \text { ) } \uparrow\end{array}$ & hsa-miR-186 & $\begin{array}{l}\text { hsa-miR-93; hsa-miR-17-5p; } \\
\text { hsa-miR-20a; hsa-miR-106b }\end{array}$ \\
\hline LMO3 (LIM domain only 3 ) & & $\begin{array}{l}\text { hsa-miR-20a; hsa-miR-93; } \\
\text { hsa-miR-17-5p; hsa-miR-183; } \\
\text { hsa-miR-106b }\end{array}$ \\
\hline NFASC (neurofascin) $\uparrow$ & hsa-miR-150 & $\begin{array}{l}\text { hsa-miR-200b; hsa-miR-200c; } \\
\text { hsa-miR-182 }\end{array}$ \\
\hline $\begin{array}{l}\text { PDE4DIP (phosphodiesterase 4D interacting } \\
\text { protein) } \uparrow\end{array}$ & & hsa-miR-183 \\
\hline PLS1 (plastin 1) $\downarrow$ & hsa-miR-30e-5p & $\begin{array}{l}\text { hsa-miR-17-5p; hsa-miR-20a; } \\
\text { hsa-miR-106b }\end{array}$ \\
\hline $\begin{array}{l}\text { PTPN3 (protein tyrosine phosphatase, } \\
\text { non-receptor type } 3 \text { ) }\end{array}$ & & $\begin{array}{l}\text { hsa-miR-17-5p; hsa-miR-20a; } \\
\text { hsa-miR-106b }\end{array}$ \\
\hline RGS2 (regulator of G-protein signalling 2) & hsa-miR-30e-5p & hsa-miR-182 \\
\hline RGS5 (regulator of G-protein signalling 5) $\uparrow$ & hsa-miR-186 & \\
\hline $\begin{array}{l}\text { RPS6KA5 (ribosomal protein S6 kinase, } \\
90 \mathrm{kDa} \text {, polypeptide 5) } \downarrow\end{array}$ & hsa-miR-148a & $\begin{array}{l}\text { hsa-miR-93; hsa-miR-17-5p; } \\
\text { hsa-miR-20a; hsa-miR-106b }\end{array}$ \\
\hline $\begin{array}{l}\text { SCAP2 (src family associated phosphoprotein } \\
2) \uparrow\end{array}$ & & hsa-miR-182 \\
\hline $\begin{array}{l}\text { SLCO3A1 (solute carrier organic anion } \\
\text { transporter family, member } 3 \mathrm{~A} 1 \text { ) } \uparrow\end{array}$ & hsa-miR-34a & hsa-miR-182 \\
\hline SNAP25 (synaptosomal-associated protein) $\uparrow$ & hsa-miR-130a; hsa-miR-1 & $\begin{array}{l}\text { hsa-miR-130b; hsa-miR-200b; } \\
\text { hsa-miR-200c }\end{array}$ \\
\hline $\begin{array}{l}\text { TNFSF12 (tumor necrosis factor superfamily, } \\
\text { member } 12) \uparrow\end{array}$ & hsa-miR-28 & \\
\hline
\end{tabular}

\section{Conclusions}

MicroRNAs are predicted to regulate a large fraction of protein-coding genes, as computational analysis reveals that an average miRNA could have as many as 100 or more target genes. On the other hand, a single gene may have target sites for several distinct miRNAs, allowing a fine tuning of gene expression by miRNAs.

In the present study, we used miRNA microarray technology to identify the miRNAs differentially expressed in paired eutopic/ectopic endometrium from the same patients and bioinformatics tools to identify their predicted targets as well as the molecular networks and the biological functions they may affect.

Comparing miRNA expression profiles among the different subjects, we identified 50 miRNAs differentially expressed in ectopic versus eutopic samples. Several of these miRNAs were also reported to be differentially expressed in two recent studies $[62,63]$, although with a modulation occasionally discordant from our results. This, joint to a notable accordance between their predicted targets and the genes reported to be differentially expressed in two studies of gene expression [23,24], consolidates the hypothesis of a possible role of miRNAs in the pathogenesis of endometriosis.

The miRNAs-predicted targets were identified by the intersection of the results from two different search algorithms, and the biological functions the differentially expressed miRNA may affect were identified by OntoExpress and IPA software. Functional analysis, performed using IPA software, was carried out uploading either the predicted targets or the differentially expressed miRNAs, thus using different databases for miRNA targets. As expected, 
TABLE 8: Molecular networks constituted by the common differentially expressed transcripts in ovarian and peritoneal endometriosis predicted to be targets of the 50 miRNAs. Differentially expressed genes common to both ovarian and peritoneal endometriosis that are predicted targets of the 50 differentially expressed miRNAs were uploaded in IPA in order to identify the molecular networks and functions to which they belong. $P<.01$.

\begin{tabular}{|c|c|c|c|c|}
\hline ID & Molecules in Network & $P$-value & $\begin{array}{c}\text { Focus } \\
\text { Molecules }\end{array}$ & Top Functions \\
\hline 1 & $\begin{array}{l}\text { CAV1, CAV2, CDKN1A, ESR1, } \\
\text { HMGA1, LPL, MMP2, NOS3, } \\
\text { SMARCA4, SP1, SP3, SRC, } \\
\text { TNFSF12, TP53 }\end{array}$ & $10 \mathrm{E}-8$ & 4 & $\begin{array}{l}\text { Cancer, Cell Cycle, Reproductive } \\
\text { System Disease }\end{array}$ \\
\hline 2 & MBD1, SLCO3A1 & $10 \mathrm{E}-2$ & 1 & $\begin{array}{l}\text { Lipid Metabolism, Molecular } \\
\text { Transport, Small Molecule } \\
\text { Biochemistry }\end{array}$ \\
\hline 3 & RGS2, TNF & $10 \mathrm{E}-2$ & 1 & $\begin{array}{l}\text { Lipid Metabolism, Small } \\
\text { Molecule Biochemistry, Cell } \\
\text { Signaling }\end{array}$ \\
\hline 4 & DMD, DTNA, DTNB & $10 \mathrm{E}-2$ & 1 & $\begin{array}{l}\text { Cellular Assembly and } \\
\text { Organization, Nervous System } \\
\text { Development and Function, } \\
\text { Skeletal and Muscular System } \\
\text { Development and Function }\end{array}$ \\
\hline 5 & FYB, GRB2, SKAP2 & $10 \mathrm{E}-2$ & 1 & $\begin{array}{l}\text { Cell-To-Cell Signaling and } \\
\text { Interaction, Cell-mediated } \\
\text { Immune Response, Cellular } \\
\text { Growth and Proliferation }\end{array}$ \\
\hline
\end{tabular}

the different algorithms used to predict miRNA targets led to the identification of different molecular networks. Still, in both cases, the identified networks contained several transcripts known to be implicated in endometriosis and with their main biological functions linked to the disease. Since the targets of miRNAs are just predictions based on mathematical algorithms, the choice of the algorithm may radically modify on the whole the list of the predicted target genes and that of the molecular networks they belong to. For this reason, the validation of miRNA targets in vitro, in a cellular system, is essential to evaluate the contribution of each miRNA to the overall modulation of gene expression.

\section{Acknowledgments}

The authors gratefully acknowledge Flavia Prodam for assistance with statistical analysis, Francesca Riboni for skilled help in collecting samples, Paolo Borasio and Chiara Airoldi for the assistance in databases analysis, and Michele Ferrara for his valuable help in preparing this manuscript. N. Filigheddu and I. Gregnanin contributed equally to this work

\section{References}

[1] R. F. Kruitwagen, L. G. Poels, W. N. P. Willemsen, I. J. Y. de Ronde, P. H. K. Jap, and R. Rolland, "Endometrial epithelial cells in peritoneal fluid during the early follicular phase," Fertility and Sterility, vol. 55, no. 2, pp. 297-303, 1991.

[2] W. P. Dmowski, R. W. Steele, and G. F. Baker, "Deficient cellular immunity in endometriosis," American Journal of Obstetrics and Gynecology, vol. 141, no. 4, pp. 377-383, 1981.
[3] S. M. Gilmore, S. Aksel, C. Hoff, and R. D. A. Peterson, "In vitro lymphocyte activity in women with endometriosis-an altered immune response?" Fertility and Sterility, vol. 58, no. 6, pp. 1148-1152, 1992.

[4] S. Z. A. Badawy, V. Cuenca, H. Freliech, and C. Stefanu, "Endometrial antibodies in serum and peritoneal fluid of infertile patients with and without endometriosis," Fertility and Sterility, vol. 53, no. 5, pp. 930-932, 1990.

[5] P. V. Taylor, M. D. Maloney, J. M. Campbell, et al., "Autoreactivity in women with endometriosis," British Journal of Obstetrics and Gynaecology, vol. 98, no. 7, pp. 680-684, 1991.

[6] A. F. Haney, J. J. Muscato, and J. B. Weinberg, "Peritoneal fluid cell populations in infertility patients," Fertility and Sterility, vol. 35, no. 6, pp. 696-698, 1981.

[7] L. Van Le, S.-T. Oh, J. A. Anners, C. A. Rinehart, and J. Halme, "Interleukin-1 inhibits growth of normal human endometrial stromal cells," Obstetrics and Gynecology, vol. 80, no. 3, pp. 405-409, 1992.

[8] D. Semer, K. Reisler, P. C. MacDonald, and M. L. Casey, "Responsiveness of human endometrial stromal cells to cytokines," Annals of the New York Academy of Sciences, vol. 622, pp. 99-110, 1991.

[9] N. Rana, D. P. Braun, R. House, H. Gebel, C. Rotman, and W. P. Dmowski, "Basal and stimulated secretion of cytokines by peritoneal macrophages in women with endometriosis," Fertility and Sterility, vol. 65, no. 5, pp. 925-930, 1996.

[10] S. E. Rier, A. K. Parsons, and J. L. Becker, "Altered interleukin6 production by peritoneal leukocytes from patients with endometriosis," Fertility and Sterility, vol. 61, no. 2, pp. 294299, 1994.

[11] I. E. Sasson and H. S. Taylor, "Stem cells and the pathogenesis of endometriosis," Annals of the New York Academy of Sciences, vol. 1127, pp. 106-115, 2008. 
[12] S. Kennedy, R. Hadfield, C. Westbrook, D. E. Weeks, D. Barlow, and S. Golding, "Magnetic resonance imaging to assess familial risk in relatives of women with endometriosis," The Lancet, vol. 352, no. 9138, pp. 1440-1441, 1998.

[13] J. L. Simpson, S. Elias, L. R. Malinak, and V. C. Buttram Jr., "Heritable aspects of endometriosis. I. Genetic studies," American Journal of Obstetrics and Gynecology, vol. 137, no. 3, pp. 327-331, 1980.

[14] D. Coxhead and E. J. Thomas, "Familial inheritance of endometriosis in a British population. A case control study," Journal of Obstetrics and Gynaecology, vol. 13, no. 1, pp. 4244, 1993.

[15] M. H. Moen and P. Magnus, "The familial risk of endometriosis," Acta Obstetricia et Gynecologica Scandinavica, vol. 72, no. 7, pp. 560-564, 1993.

[16] S. Kennedy, R. Hadfield, H. Mardon, and D. Barlow, "Age of onset of pain symptoms in non-twin sisters concordant for endometriosis," Human Reproduction, vol. 11, no. 2, pp. 403405, 1996.

[17] S. Kennedy, "The genetics of endometriosis," European Journal of Obstetrics Gynecology and Reproductive Biology, vol. 82, no. 2, pp. 129-133, 1999.

[18] S. Kennedy, S. Bennett, and D. E. Weeks, "Affected sib-pair analysis in endometriosis," Human Reproduction Update, vol. 7, no. 4, pp. 411-418, 2001.

[19] J. Meola, J. C. Rosa e Silva, D. B. Dentillo, et al., "Differentially expressed genes in eutopic and ectopic endometrium of women with endometriosis," 2009, Fertility and Sterility. [Epub ahead of print].

[20] H. Honda, F. F. Barrueto, J. Gogusev, D. D. Im, and P. J. Morin, "Serial analysis of gene expression reveals differential expression between endometriosis and normal endometrium. Possible roles for AXL and SHC1 in the pathogenesis of endometriosis," Reproductive Biology and Endocrinology, vol. 6, article 59, 2008.

[21] W.-P. Hu, S. K. Tay, and Y. Zhao, "Endometriosis-specific genes identified by real-time reverse transcription-polymerase chain reaction expression profiling of endometriosis versus autologous uterine endometrium," Journal of Clinical Endocrinology and Metabolism, vol. 91, no. 1, pp. 228-238, 2006.

[22] Y. Wu, A. Kajdacsy-Balla, E. Strawn, et al., "Transcriptional characterizations of differences between eutopic and ectopic endometrium," Endocrinology, vol. 147, no. 1, pp. 232-246, 2006.

[23] K. M. Eyster, O. Klinkova, V. Kennedy, and K. A. Hansen, "Whole genome deoxyribonucleic acid microarray analysis of gene expression in ectopic versus eutopic endometrium," Fertility and Sterility, vol. 88, no. 6, pp. 1505-1533, 2007.

[24] M. L. Hull, C. R. Escareno, J. M. Godsland, et al., "Endometrial-peritoneal interactions during endometriotic lesion establishment," American Journal of Pathology, vol. 173, no. 3, pp. 700-715, 2008.

[25] R. C. Lee, R. L. Feinbaum, and V. Ambros, "The C. elegance heterochronic gene lin-4 encodes small RNAs with antisense complementarity to lin-14," Cell, vol. 75, pp. 843-854, 1993.

[26] E. C. Lai, P. Tomancak, R. W. Williams, and G. M. Rubin, "Computational identification of Drosophila microRNA genes," Genome Biology, vol. 4, no. 7, article R42, 2003.

[27] L. P. Lim, N. C. Lau, E. G. Weinstein, et al., "The microRNAs of Caenorhabditis elegans," Genes and Development, vol. 17, no. 8, pp. 991-1008, 2003.

[28] L. P. Lim, N. C. Lau, P. Garrett-Engele, et al., "Microarray analysis shows that some microRNAs downregulate large numbers of-target mRNAs," Nature, vol. 433, no. 7027, pp. 769-773, 2005.

[29] B. P. Lewis, C. B. Burge, and D. P. Bartel, "Conserved seed pairing, often flanked by adenosines, indicates that thousands of human genes are microRNA targets," Cell, vol. 120, no. 1, pp. 15-20, 2005.

[30] P. Xu, S. Y. Vernooy, M. Guo, and B. A. Hay, "The Drosophila microRNA mir-14 suppresses cell death and is required for normal fat metabolism," Current Biology, vol. 13, no. 9, pp. 790-795, 2003.

[31] J. Brennecke, D. R. Hipfner, A. Stark, R. B. Russell, and S. M. Cohen, "bantam encodes a developmentally regulated microRNA that controls cell proliferation and regulates the proapoptotic gene hid in Drosophila," Cell, vol. 113, no. 1, pp. 25-36, 2003.

[32] J. Dostie, Z. Mourelatos, M. Yang, A. Sharma, and G. Dreyfuss, "Numerous microRNPs in neuronal cells containing novel microRNAs," RNA, vol. 9, no. 2, pp. 180-186, 2003.

[33] J. Dostie, Z. Mourelatos, M. Yang, A. Sharma, and G. Dreyfuss, "Erratum: numerous microRNPs in neuronal cells containing novel microRNAs," RNA, vol. 9, no. 5, pp. 631-632, 2003.

[34] V. Ambros, "The functions of animal microRNAs," Nature, vol. 431, no. 7006, pp. 350-355, 2004.

[35] B. M. Engels and G. Hutvagner, "Principles and effects of microRNA-mediated post-transcriptional gene regulation," Oncogene, vol. 25, no. 46, pp. 6163-6169, 2006.

[36] M. Jovanovic and M. O. Hengartner, "miRNAs and apoptosis: RNAs to die for," Oncogene, vol. 25, no. 46, pp. 6176-6187, 2006.

[37] R. Garzon, M. Fabbri, A. Cimmino, G. A. Calin, and C. M. Croce, "MicroRNA expression and function in cancer," Trends in Molecular Medicine, vol. 12, no. 12, pp. 580-587, 2006.

[38] G. A. Calin and C. M. Croce, "MicroRNA signatures in human cancers," Nature Reviews Cancer, vol. 6, no. 11, pp. 857-866, 2006.

[39] M. Canis, J. G. Donnez, D. S. Guzick, et al., "Revised american society for reproductive medicine classification of endometriosis: 1996," Fertility and Sterility, vol. 67, no. 5, pp. 817-821, 1997.

[40] X. Gao, E. Gulari, and X. Zhou, "In situ synthesis of oligonucleotide microarrays," Biopolymers, vol. 73, no. 5, pp. 579-596, 2004.

[41] Q. Zhu, A. Hong, N. Sheng, et al., "microParaflo biochip for nucleic acid and protein analysis," Methods in Molecular Biology, vol. 382, pp. 287-312, 2007.

[42] B. M. Bolstad, R. A. Irizarry, M. Astrandand, and T. P. Speed, "A comparison of normalization methods for high density oligonucleotide array data based on variance and bias," Bioinformatics, vol. 19, no. 2, pp. 185-193, 2003.

[43] W. Pan, "A comparative review of statistical methods for discovering differentially expressed genes in replicated microarray experiments," Bioinformatics, vol. 18, no. 4, pp. 546-554, 2002.

[44] M. B. Eisen, P. T. Spellman, P. O. Brown, and D. Botstein, "Cluster analysis and display of genome-wide expression patterns," Proceedings of the National Academy of Sciences of the United States of America, vol. 95, no. 25, pp. 14863-14868, 1998.

[45] M. Fabbri, R. Garzon, A. Cimmino, et al., "MicroRNA29 family reverts aberrant methylation in lung cancer by targeting DNA methyltransferases 3A and 3B," Proceedings of the National Academy of Sciences of the United States of America, vol. 104, no. 40, pp. 15805-15810, 2007. 
[46] A. M. Duursma, M. Kedde, M. Schrier, C. le Sage, and R. Agami, "miR-148 targets human DNMT3b protein coding region," RNA, vol. 14, no. 5, pp. 872-877, 2008.

[47] P. A. Jones and S. B. Baylin, "The epigenomics of cancer," Cell, vol. 128, no. 4, pp. 683-692, 2007.

[48] Y. Wu, E. Strawn, Z. Basir, G. Halverson, and S.-W. Guo, "Aberrant expression of deoxyribonucleic acid methyltransferases DNMT1, DNMT3A, and DNMT3B in women with endometriosis," Fertility and Sterility, vol. 87, no. 1, pp. 24-32, 2007.

[49] A. Kharfi, Y. Labelle, J. Mailloux, and A. Akoum, "Deficient expression of tumor necrosis factor receptor type 2 in the endometrium of women with endometriosis," American Journal of Reproductive Immunology, vol. 50, no. 1, pp. 33-40, 2003.

[50] Y. S. Antsiferova, N. Yu. Sotnikova, L. V. Posiseeva, and A. L. Shor, "Changes in the T-helper cytokine profile and in lymphocyte activation at the systemic and local levels in women with endometriosis," Fertility and Sterility, vol. 84, no. 6, pp. 1705-1711, 2005.

[51] O. A. Odukoya, R. Ajjan, K. Lim, P. F. Watson, A. P. Weetman, and I. D. Cooke, "The pattern of cytokine mRNA expression in ovarian endometriomata," Molecular Human Reproduction, vol. 3, no. 5, pp. 393-397, 1997.

[52] T. Tsudo, T. Harada, T. Iwabe, et al., "Altered gene expression and secretion of interleukin-6 in stromal cells derived from endometriotic tissues," Fertility and Sterility, vol. 73, no. 2, pp. 205-211, 2000.

[53] C. M. Kyama, L. Overbergh, S. Debrock, et al., "Increased peritoneal and endometrial gene expression of biologically relevant cytokines and growth factors during the menstrual phase in women with endometriosis," Fertility and Sterility, vol. 85, no. 6, pp. 1667-1675, 2006.

[54] R. O. Burney, S. Talbi, A. E. Hamilton, et al., "Gene expression analysis of endometrium reveals progesterone resistance and candidate susceptibility genes in women with endometriosis," Endocrinology, vol. 148, no. 8, pp. 3814-3826, 2007.

[55] K. Shazand, S. Baban, C. Prive, et al., "FOXO1 and c-jun transcription factors mRNA are modulated in endometriosis," Molecular Human Reproduction, vol. 10, no. 12, pp. 871-877, 2004.

[56] S. Matsuzaki, M. Canis, C. Vaurs-Barrière, O. BoespflugTanguy, B. Dastugue, and G. Mage, "DNA microarray analysis of gene expression in eutopic endometrium from patients with deep endometriosis using laser capture microdissection," Fertility and Sterility, vol. 84, supplement 2, pp. 1180-1190, 2005.

[57] P. A. Gregory, A. G. Bert, E. L. Paterson, et al., "The miR200 family and miR-205 regulate epithelial to mesenchymal transition by targeting ZEB1 and SIP1," Nature Cell Biology, vol. 10, no. 5, pp. 593-601, 2008.

[58] P. Khatri, P. Bhavsar, G. Bawa, and S. Draghici, “Onto-tools: an ensemble of web-accessible ontology-based tools for the functional design and interpretation of high-throughput gene expression experiments," Nucleic Acids Research, vol. 32, pp. W449-W456, 2004.

[59] S. Draghici, P. Khatri, A. L. Tarca, et al., "A systems biology approach for pathway level analysis," Genome Research, vol. 17, no. 10, pp. 1537-1545, 2007.

[60] Y. Zhou, R.-A. F. Gunput, and R. J. Pasterkamp, "Semaphorin signaling: progress made and promises ahead," Trends in Biochemical Sciences, vol. 33, no. 4, pp. 161-170, 2008.
[61] F. Shen, X. Liu, J.-G. Geng, and S.-W. Guo, "Increased immunoreactivity to SLIT/ROBO1 in ovarian endometriomas: a likely constituent biomarker for recurrence," American Journal of Pathology, vol. 175, no. 2, pp. 479-488, 2009.

[62] Q. Pan, X. Luo, T. Toloubeydokhti, and N. Chegini, "The expression profile of micro-RNA in endometrium and endometriosis and the influence of ovarian steroids on their expression," Molecular Human Reproduction, vol. 13, no. 11, pp. 797-806, 2007.

[63] E. M. C. O. Teague, K. H. Van der Hoek, M. B. Van der Hoek, et al., "MicroRNA-regulated pathways associated with endometriosis," Molecular Endocrinology, vol. 23, no. 2, pp. 265-275, 2009. 


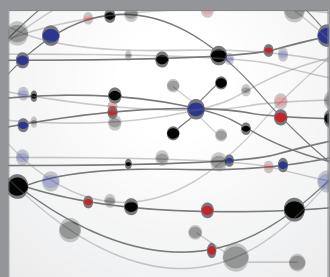

The Scientific World Journal
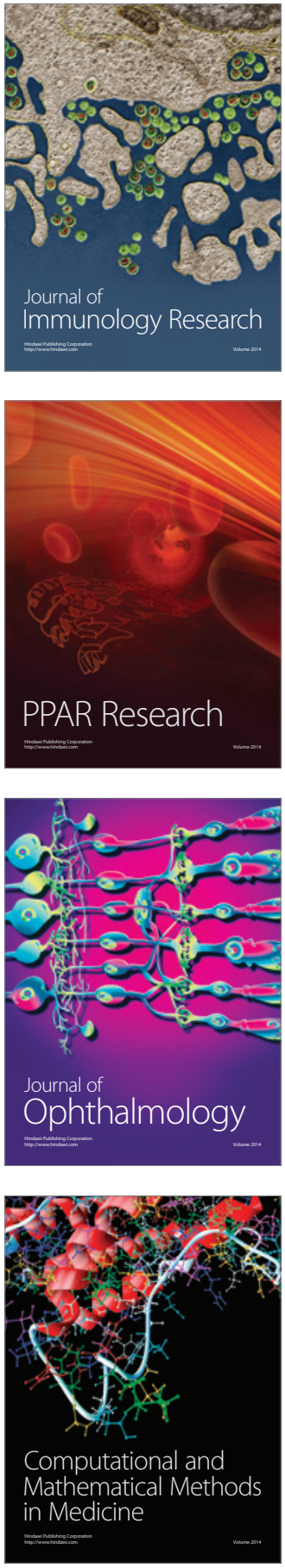

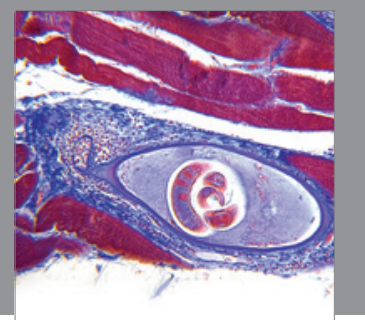

Gastroenterology

Research and Practice
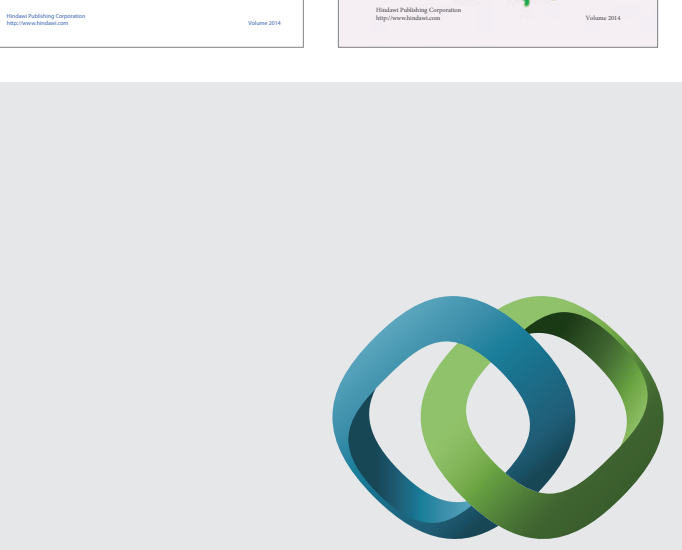

\section{Hindawi}

Submit your manuscripts at

http://www.hindawi.com
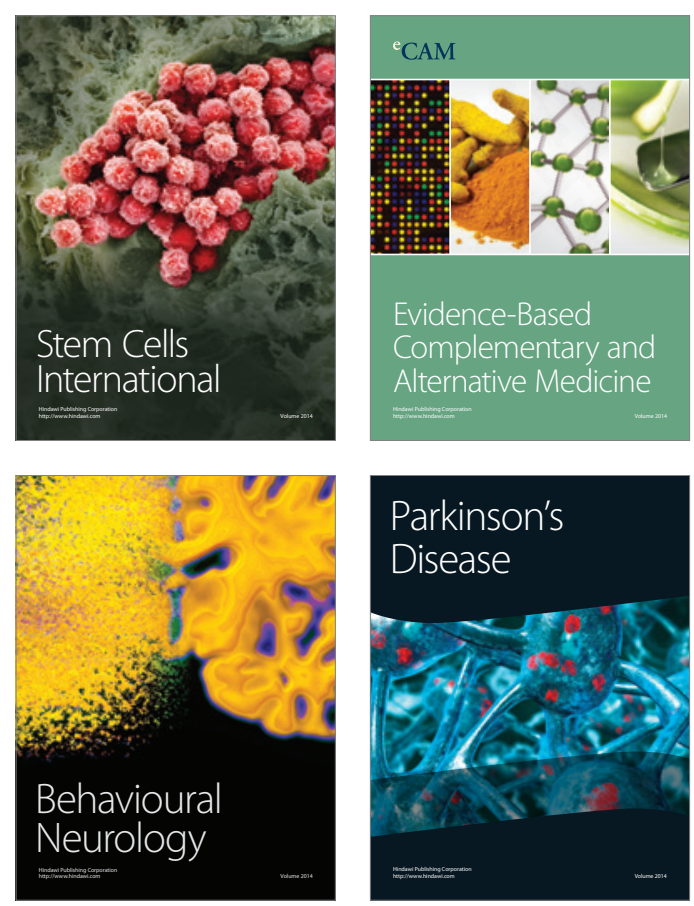

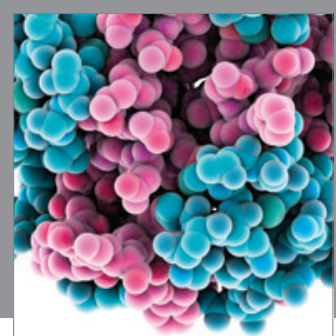

Journal of
Diabetes Research

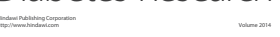

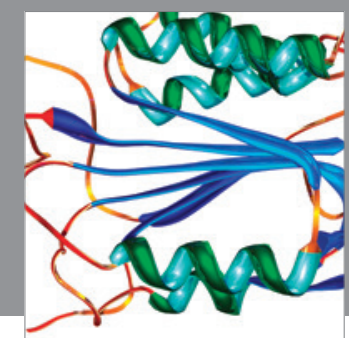

Disease Markers
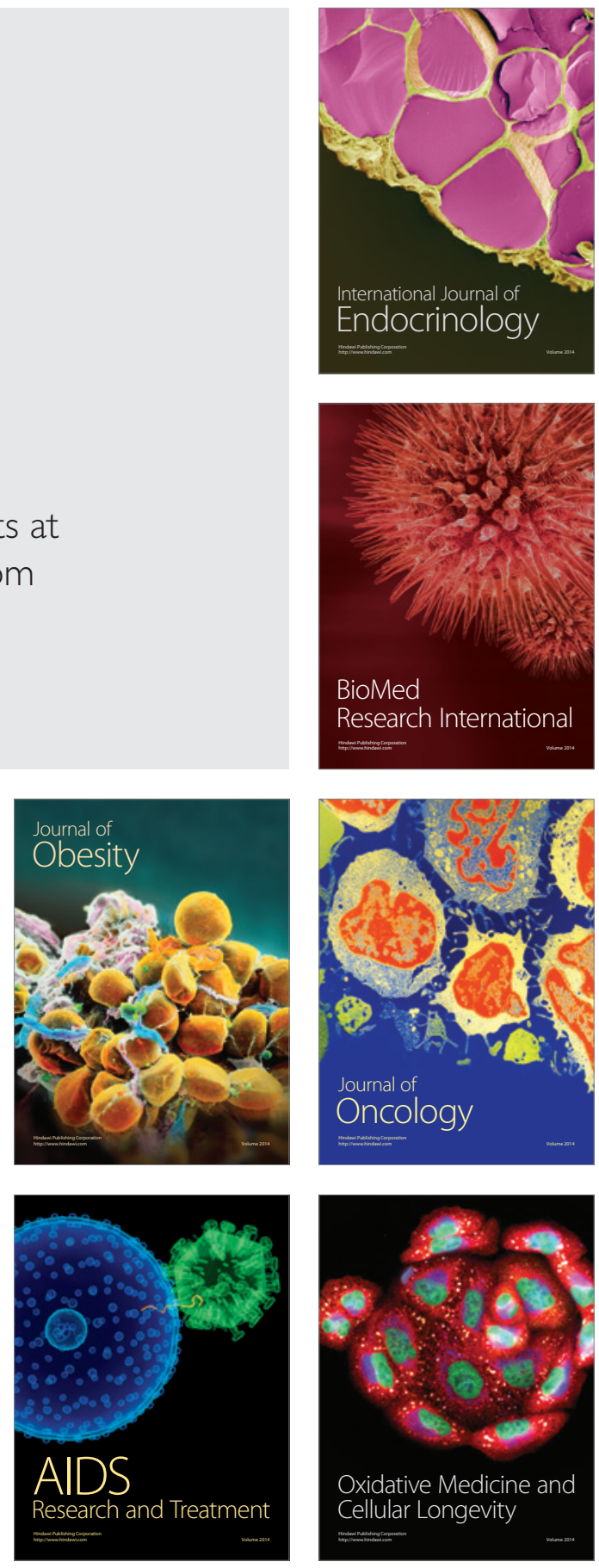